\title{
Article \\ Dynamic Response of Rock-like Materials Based on SHPB Pulse Waveform Characteristics
}

\author{
Bi Sun ${ }^{1,2} \mathbb{D}$, Rui Chen ${ }^{1}$, Yang Ping ${ }^{3}$, Zhende Zhu ${ }^{4}$, Nan $\mathrm{Wu}^{5}{ }^{\mathbb{D}}$ and Yanxin He ${ }^{4, *(\mathbb{D})}$ \\ 1 Harbin Institute of Technology (Shenzhen), Shenzhen 518055, China; sunbi58@126.com (B.S.); \\ cechenrui@hit.edu.cn (R.C.) \\ 2 Shenzhen Water Planning and Design Institute Co., Ltd., Shenzhen 518001, China \\ 3 PowerChina Eco-Environment Group Co., Ltd., Shenzhen 518102, China; pingy@swpdi.com \\ 4 Key Laboratory of Ministry of Education of Geomechanics and Embankment Engineering, Hohai University, \\ Nanjing 210098, China; zhendezhunj@163.com \\ 5 Guangzhou University-Tamkang University Joint Research Centre for Engineering Structure Disaster \\ Prevention and Control, Guangzhou University, Guangzhou 510006, China; wunan@gzhu.edu.cn \\ * Correspondence: yxhe@hhu.edu.cn
}

check for updates

Citation: Sun, B.; Chen, R.; Ping, Y.; Zhu, Z.; Wu, N.; He, Y. Dynamic Response of Rock-like Materials Based on SHPB Pulse Waveform Characteristics. Materials 2022, 15, 210 https://doi.org/10.3390/ma15010210

Academic Editors: Jan Awrejcewicz, José M. Vega, Hari Mohan Srivastava, Ying-Cheng Lai, Hamed Farokhi and Roman Starosta

Received: 29 November 2021

Accepted: 25 December 2021

Published: 28 December 2021

Publisher's Note: MDPI stays neutral with regard to jurisdictional claims in published maps and institutional affiliations.

Copyright: (C) 2021 by the authors. Licensee MDPI, Basel, Switzerland. This article is an open access article distributed under the terms and conditions of the Creative Commons Attribution (CC BY) license (https:// creativecommons.org/licenses/by/ $4.0 /)$.

\begin{abstract}
Rock-like brittle materials under dynamic load will show more complex dynamic mechanical properties than those under static load. The relationship between pulse waveform characteristics and strain rate effect and inertia effect is rarely discussed in the split-Hopkinson pressure bar (SHPB) numerical simulation research. In response to this problem, this paper discusses the effects of different pulse types and pulse waveforms on the incident waveform and dynamic response characteristics of specimens based on particle flow code (PFC). The research identifies a critical interval of rock dynamic strength, where the dynamic strength of the specimen is independent of the strain rate but increases with the amplitude of the incident stress wave. When the critical interval is exceeded, the dynamic strength is determined by the strain rate and strain rate gradient. The strain rate of the specimen is only related to the slope of the incident stress wave and is independent of its amplitude. It is also determined that the inertia effect cannot be eliminated in the SHPB. The slope of the velocity pulse waveform determines the strain rate of the specimen, the slope of the force pulse waveform determines the strain rate gradient of the specimen, and the upper bottom time determines the strain rate of the specimen. It provides a reference for SHPB numerical simulation. A dynamic strength prediction model of rock-like materials is then proposed, which considers the effects of strain rate and strain rate gradient.
\end{abstract}

Keywords: SHPB; waveform characteristics; strain rate; strain rate gradient; particle flow code

\section{Introduction}

The split-Hopkinson pressure bar (SHPB) is an important piece of testing equipment for analyzing the dynamic mechanical properties of materials and is widely used in dynamic mechanical response analysis of rock-like brittle materials [1,2]. Rock-like brittle materials under dynamic load show more complex dynamic mechanical properties than those under static load [3]. The scatter that characterizes the experimental data contributes to the uncertainty and difficulty of interpreting such data [4]. Therefore, in order to obtain effective and accurate test data, constant strain rate deformation of the specimen must be guaranteed in the SHPB test [5,6].

Because the failure strain of rock-like brittle materials is very low, they often fail without reaching a constant strain rate under the condition of high-speed impact. In order to study the dynamic characteristics of rock-like brittle materials, many scholars first analyzed whether the incident wave waveform met the constant strain rate deformation of the specimen $[7,8]$. In early SHPB test research, the fatal effect of strain rate on the test results was not recognized $[9,10]$. It was determined that a pulse shaper could delay the rise 
time of the incident wave, and its appearance effectively improved the waveform [11-13]. Luo et al. [14] used an H62 brass sheet with a thickness of $2.5 \mathrm{~mm}$ and a diameter ranging from 3 to $10 \mathrm{~mm}$ as a pulse shaper to obtain different waveforms to achieve constant strain rate loading. Jiang et al. [15] obtained different dynamic strain rate-strain curves by different air gun pressures. Bagher et al. [16] studied the effects of striker bar velocity, diameter, and thickness of the pulse shaper on shaping pulses by SHPB tests experimentally and numerically. The shaping effect of hyperelastic alloy [17], copper material, or other soft materials [18,19] was also found to meet the constant strain rate deformation of rock. The incident waveform could also be artificially controlled by a variable cross-section incident bar [20] or special shape striker [21]. The results of numerical simulations showed that soft materials had more advantages in modifying the waveform [7,22]. Zhou et al. [23] carried out SHPB numerical simulation experiment by applying different impact speeds directly on the special-shaped striker. Kucewicz et al. [24] used a pulse shaper with a radius of $8 \mathrm{~mm}$ to conduct an SHPB experiment by LS-DYNA. Jankowiak et al. [25] used a cylindrical copper shaper with $20 \mathrm{~mm}$ diameter and $1 \mathrm{~mm}$ thickness. Baranowsk et al. [26] used three numerical modeling methods to establish the pulse shaper model to study the influence of mesh (particle) sensitivity on the characteristics of incident pulses.

The dynamic increase factor (DIF) can describe the variation of dynamic strength with strain rate. The dynamic strength of rock material DIF was found to have an exponential relation with the strain rate [27-29]. However, the test data often showed great discreteness $[30,31]$ because the inertia effect was ignored. The inertia effect cannot be eliminated during dynamic loading [32] and is also a part of the macro-bearing capacity. While it is known that the inertia effect is caused by the rapid increase of specimens strain rate in a short time, there is no unified understanding of it at present. Rossi and other scholars $[33,34]$ believed that the inertia effect became dominant under high strain rate; Guo et al. [35] determined that the inertia effect was significant when the strain rate was greater than 100/s; Zhou et al. [36] believed that the increase of material dynamic strength was due to the inertia effect rather than the strain rate effect; other scholars also put forward the dynamic strength criterion that considered the inertia effect to describe the dynamic strength of rock materials [37-39]. Li et al. [40] believed that the enhancement of the apparent dynamic strength of concrete materials is caused by the lateral inertial constraint rather than the strain rate sensitivity of the tested materials. Katayama et al. [41] considered if the mass is retained, then conservation of inertia and spatial continuity of inertia are maintained. The quadratic equation is used to describe the relation between DIF and $\log _{10}$ of the strain rate. Hao et al. [42-44] also used the quadratic equation to express the DIF model after considering lateral inertia. Al-Salloum [45] used the power function to express the DIF model. Lee et al. [46,47] proposed a new concrete DIF that excludes inertia effects by considering the strain acceleration and geometry of the specimens based on SHPB test results.

Numerical simulation is an important means to study the SHPB test [23]. Based on the particle flow code 2D (PFC2D) framework, this paper discusses the effects of different pulse types and waveforms on the specimen's incident waveform and dynamic response characteristics. On the basis of previous theoretical analysis and numerical calculation results, a dynamic strength prediction model of rock-like brittle material is then proposed. This model comprehensively considers the effects of strain rate and strain rate gradient on macro dynamic strength.

\section{Micro Model}

The PFC2D framework was selected to simulate our SHPB impact experiment as it provides both a scientific tool to investigate the micromechanisms that combine to produce complex macroscopic behaviors and an engineering tool to predict these macroscopic behaviors [48]. PFC2D can be used to simulate many scientific problems in rock mechanics and rock engineering [49], and it is also widely used in SHPB dynamic testing [23,50-53]. 


\subsection{Contact Bond Model}

The PFC2D bonding model consists of a material system composed of grains and cement materials to jointly describe the micromechanical behavior of rock materials [54]. Grains and cement materials can be simplified into a spring and are equivalent to two microbeams, respectively, as shown in Figure 1. The framework includes two basic bonding models: parallel bond model (PBM) and contact bond model (CBM). The PBM provides the force-displacement behavior of a finite-sized piece of cementitious material deposited between two pieces, acting in parallel with a linear model [53]. The particle can freely move in the shear and normal direction and rotate between particles. The CBM is a simplification of the PBM [54]; that is, when the radius $\bar{R}$ (see Figure 1b) of the microbeam composed of the cement material is 0 , the bond contact degenerates to one point. We employ the $\mathrm{CBM}$ for numerical simulation in this work. Although the microbeam of CBM cannot resist bending moment, it still has bond strength.

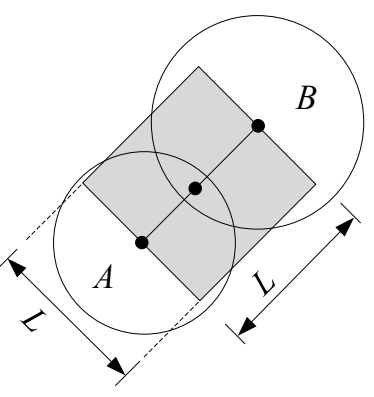

(a)

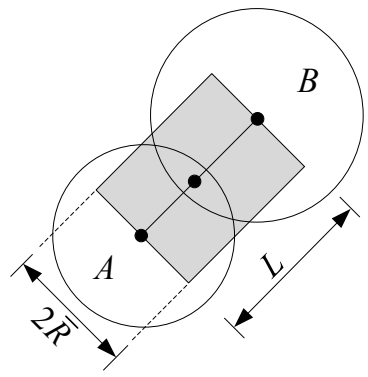

(b)

Figure 1. Equivalent meso-beam model of the grain-cement system [54]. (a) Grain behavior; (b) cement behavior.

The expression of contact force $F_{c}$ in the CBM is [48]:

$$
\begin{gathered}
F_{\mathrm{c}}=F_{\eta}+F_{1} \\
F_{1}=k \delta \\
F_{\eta}=2 \beta \sqrt{m k} \dot{\delta}
\end{gathered}
$$

where $F_{1}$ is linear force, $F_{\eta}$ is the damping force, $\beta$ is the damping ratio, $m$ is the particle mass, $k$ is the contact stiffness, and $\delta, \dot{\delta}$ are displacement and velocity, respectively.

The microbeam length $L=R_{\mathrm{A}}+R_{\mathrm{B}}, R_{\mathrm{A}}, R_{\mathrm{B}}$ is the radius of particles $\mathrm{A}, \mathrm{B}$, respectively; The microbeam width $2 \bar{R}$ is taken as the average value, i.e., $2 \bar{R}=2 \times\left(R_{\mathrm{A}}+R_{\mathrm{B}}\right) / 2=R_{\mathrm{A}}+$ $R_{\mathrm{B}}=L$; The microbeam thickness (particle disc thickness) is $h$ ( $h=1$ in PFC2D). Therefore, the particle contact area $A_{\mathrm{c}}=L h=L$. After simultaneously calculating Equations (1)-(3), and dividing by, divide by $A_{\mathrm{c}}$, we obtain

$$
\sigma_{\mathrm{c}}^{\prime}=k \varepsilon_{\mathrm{c}}^{\prime}+\eta_{\mathrm{c}} \dot{\varepsilon}_{\mathrm{c}}^{\prime}
$$

where $\sigma_{\mathrm{c}}^{\prime}$ is the micro-contact stress, $\varepsilon_{\mathrm{c}}^{\prime}$ is micro-strain, $\dot{\varepsilon}_{\mathrm{c}}^{\prime}$ is the micro-strain rate, $\eta_{\mathrm{c}}=$ $2 \beta \sqrt{m k}$ is the micro-damping coefficient.

\subsection{SHPB Model}

The numerical SHPB model is established, and its size is shown in Figure 2. The contact bond strength of bars and striker is selected to be high enough to avoid damage during the impact test. To enhance the contact between the specimen and the bar, the boundary particles at the contact between the bar and the bullet and between the bar and the specimen are refined into four layers. The refined particles have a radius of $0.3 \mathrm{~mm}$ and are aligned regularly [23], as illustrated in Figure 2. The radius and position of randomly 
generated particles obey uniform distribution within a limited range. The linear contact model is used between the bar and the bullet and between the bar and the specimen to simulate the state of contact without a bond. Three measuring circles are set on the incident bar, and one measuring circle is set on the transmission bar. The radius of the measuring circles is $20 \mathrm{~mm}$, and the centers of measuring circles 1, 2, and 3 are 1150, 950, and $75 \mathrm{~mm}$ away from the right end of the incident bar, respectively. Measuring circle 5 is $375 \mathrm{~mm}$ away from the left end of the transmitted bar. Another measuring circle, 4, with a radius of $12.5 \mathrm{~mm}$, is set on the specimen. The employed micro-parameters refer to references $[22,50,55]$, as shown in Table 1.

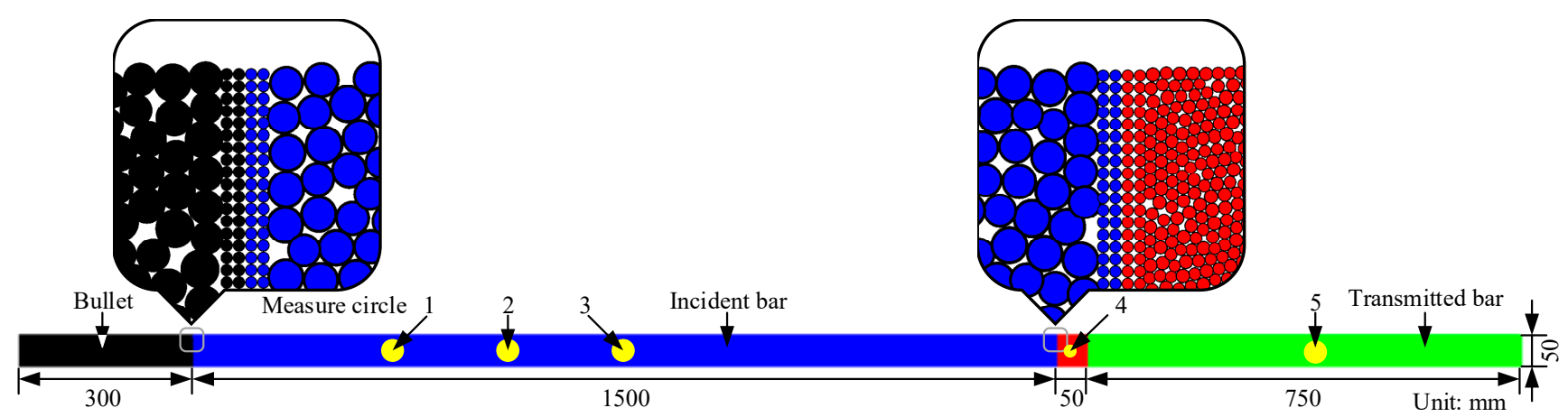

Figure 2. SHPB model.

Table 1. Micro-parameters of PFC model.

\begin{tabular}{ccccccc}
\hline Material & $\begin{array}{c}\text { Particle } \\
\text { Radius } \\
\mathbf{( m m )}\end{array}$ & $\begin{array}{c}\text { Density } \\
\mathbf{( k g \cdot \mathbf { m } ^ { - 3 } )}\end{array}$ & $\begin{array}{c}\text { Effective } \\
\text { Modulus } \\
\mathbf{( G P a )}\end{array}$ & $\begin{array}{c}\text { Normal-to- } \\
\text { Shear Stiffness } \\
\text { Ratio }\end{array}$ & $\begin{array}{c}\text { Shear } \\
\text { Strength } \\
\mathbf{( M P a )}\end{array}$ & $\begin{array}{c}\text { Tensile } \\
\text { Strength } \\
\mathbf{( M P a})\end{array}$ \\
\hline Steel bar & $0.8-0.96$ & 7800 & 300 & 3.0 & $1 \times 10^{100}$ & $1 \times 10^{100}$ \\
Specimen & $0.3-0.36$ & 2500 & 63 & 2.0 & 135 & 135 \\
\hline
\end{tabular}

\subsection{Waveform Test}

In order to investigate the influence of waveform characteristics on the dynamic response of rock specimens, two pulse types are used: velocity pulse and force pulse. The loading curve is designed as a trapezoid to control the shape of the waveform. To express the characteristics of the waveform, the waveform is controlled by amplitude, rise time, and the duration of the trapezoidal upper bottom. After many simulation tests, it is found that the trapezoidal upper bottom time has little effect on the test results for the velocity pulse. When it is taken as 0 , the loading curve is too sharp and is inconsistent with the actual waveform curve. On the premise of not affecting the calculation results and reducing the calculation time, the bottom time is set to $10 \mu \mathrm{s}$. As the rise time and bottom time of the pulse waveform significantly influence the force pulse calculation results, the pulse shape is adjusted according to the calculation requirements. The rise and fall times of the pulse curve are the same in the two pulse modes. Two typical pulse waveforms are shown in Figure 3.

Using the pulse waveform curve in Figure 3b, the stress waveform on the Hopkinson bars is obtained, as shown in Figure 4. In the figure, the stress waveforms measured by measuring circles 1,2, and 3 on the incident bar are almost the same, indicating that the waveform has no obvious dispersion phenomenon. Additionally, the stress waveforms measured by measuring circles 1, 2, and 3 on the incident bar are almost the same, indicating that the incident wave has no obvious dispersion phenomenon. Thus, it can be determined that the established SHPB numerical model is basically reliable. 


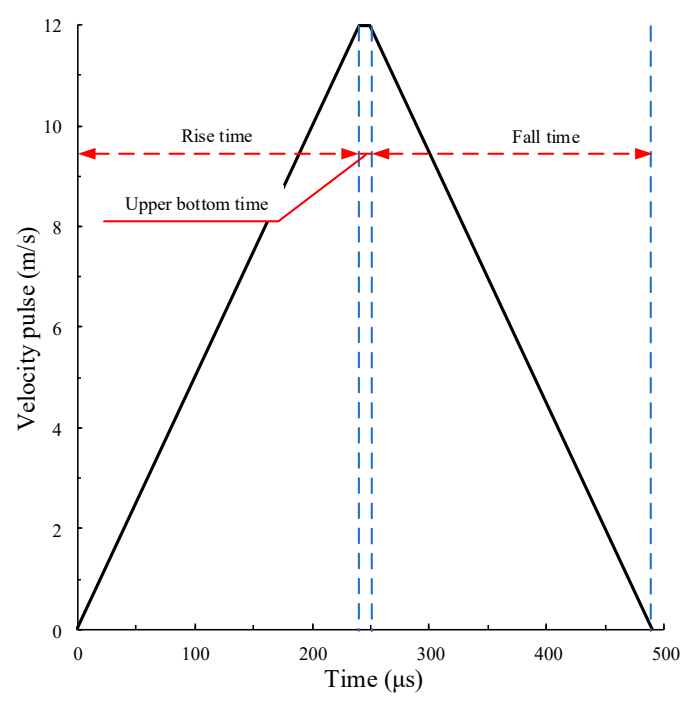

(a)

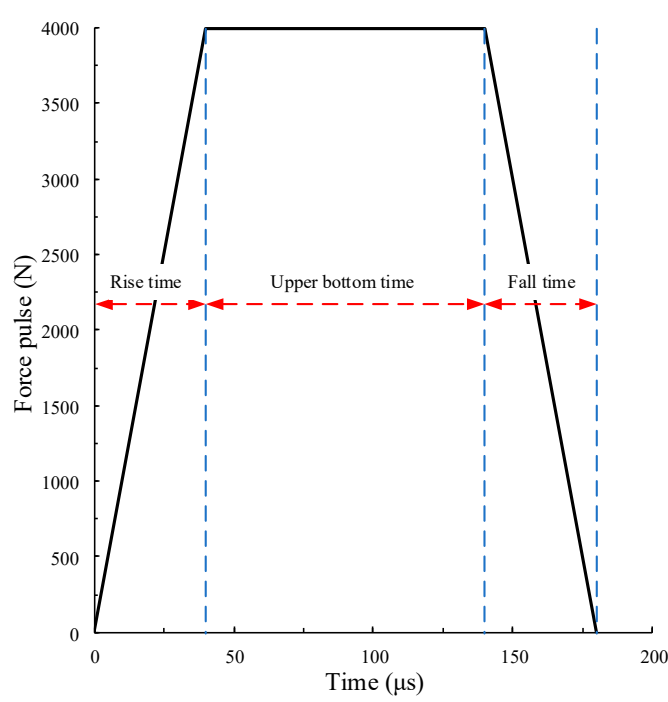

(b)

Figure 3. Typical pulse waveforms. (a) Velocity pulse; (b) force pulse.

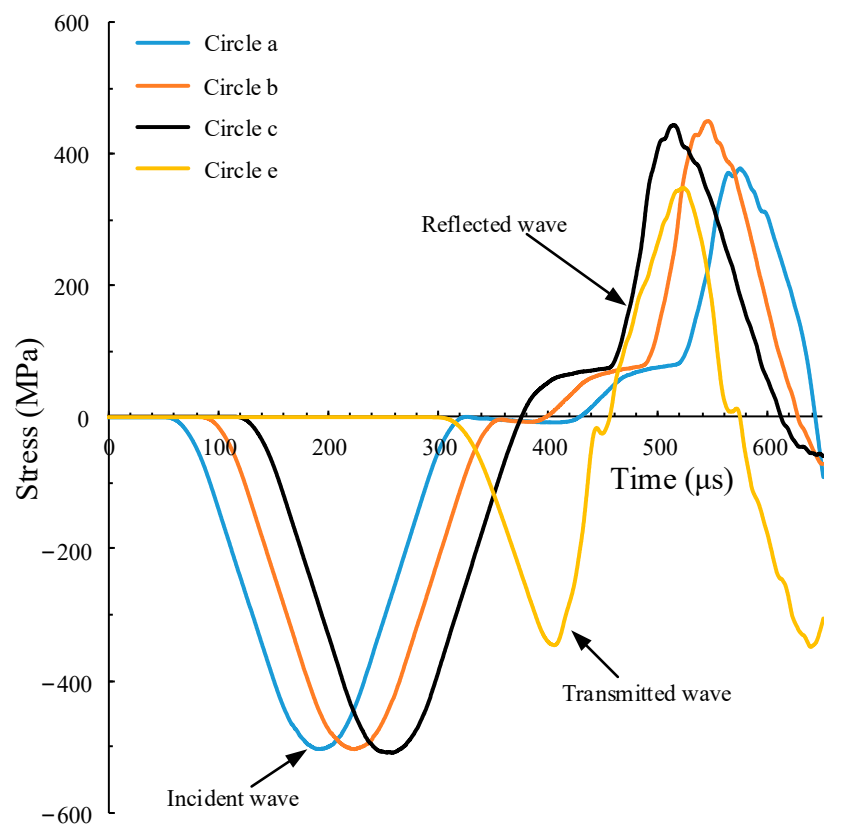

Figure 4. Stress waves recorded on the Hopkinson bars.

\section{Velocity Pulse}

\subsection{Pulse Waveform}

The shape of the velocity pulse waveform is controlled by changing amplitude $A_{\mathrm{V}}$ and rise time $t_{\mathrm{r}}$. We study the law of rock dynamic response in this paper. Five groups of velocity pulses with different amplitudes and the same slope of the rising section curve are adopted, as shown in Figure $5 \mathrm{a}$. The slope of the five groups of pulse curves is $50,000 \mathrm{~m} / \mathrm{s}^{2}$. The amplitude $A_{\mathrm{v}}=8,10,12,14$ and $16 \mathrm{~m} / \mathrm{s}$, respectively. Five groups of velocity pulses with the same amplitude and different slopes of the rising section curve are adopted, in which the slope of the pulse curve is controlled by rise time $t_{\mathrm{r}}$, as shown in Figure $5 \mathrm{~b}$. The rise time $t_{\mathrm{r}}=50,100,150,200$ and $250 \mu$ s respectively, and $A_{\mathrm{v}}=12 \mathrm{~m} / \mathrm{s}$. 


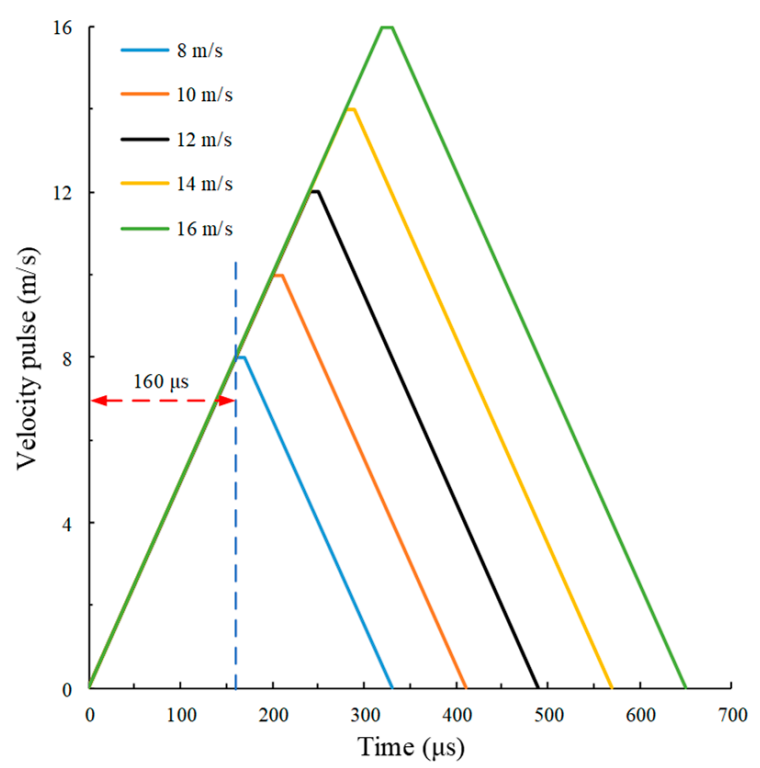

(a)

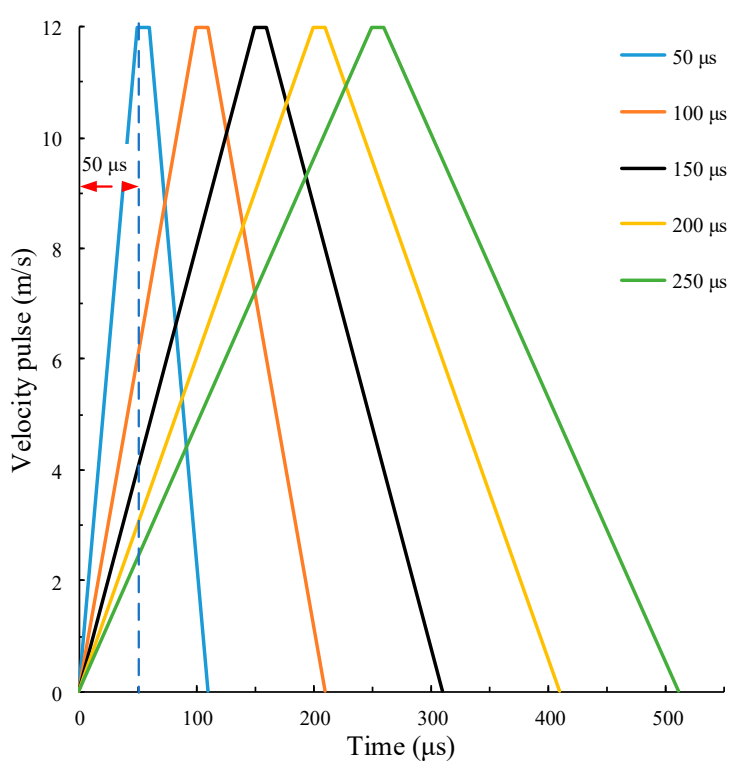

(b)

Figure 5. Velocity pulse waveform. (a) Different amplitude; (b) different rise time.

\subsection{Different Amplitudes}

The numerical calculation results of different amplitudes are shown in Figure 6. The strain and strain rate $\dot{\varepsilon}_{\mathrm{c}}$ of the specimen can be obtained by monitoring the displacement of the particles at the left and right ends of the specimen. The strain rate $\dot{\varepsilon}_{\mathrm{c}}$ is obtained by the derivative of the strain $\varepsilon_{\mathrm{c}}$ to time.

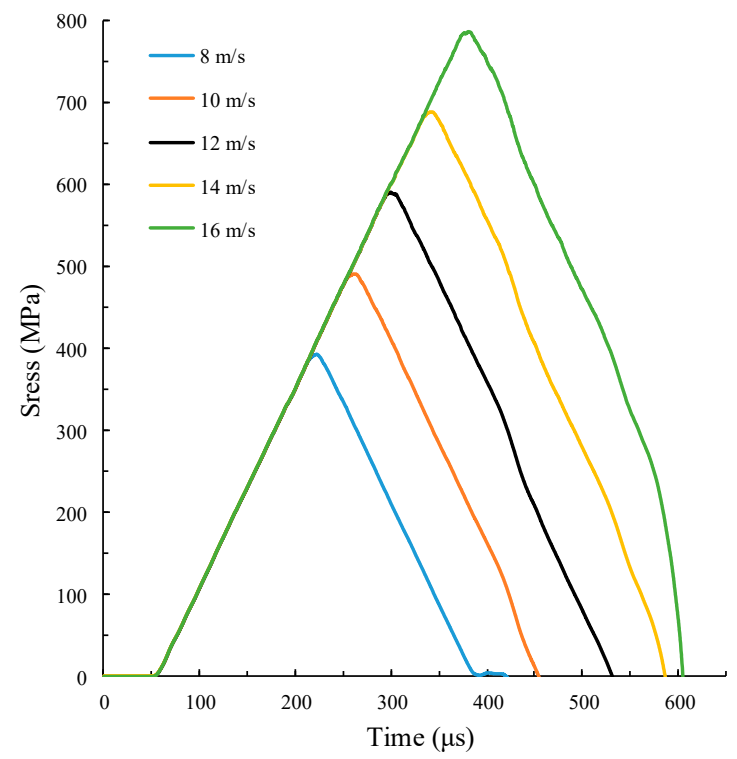

(a)

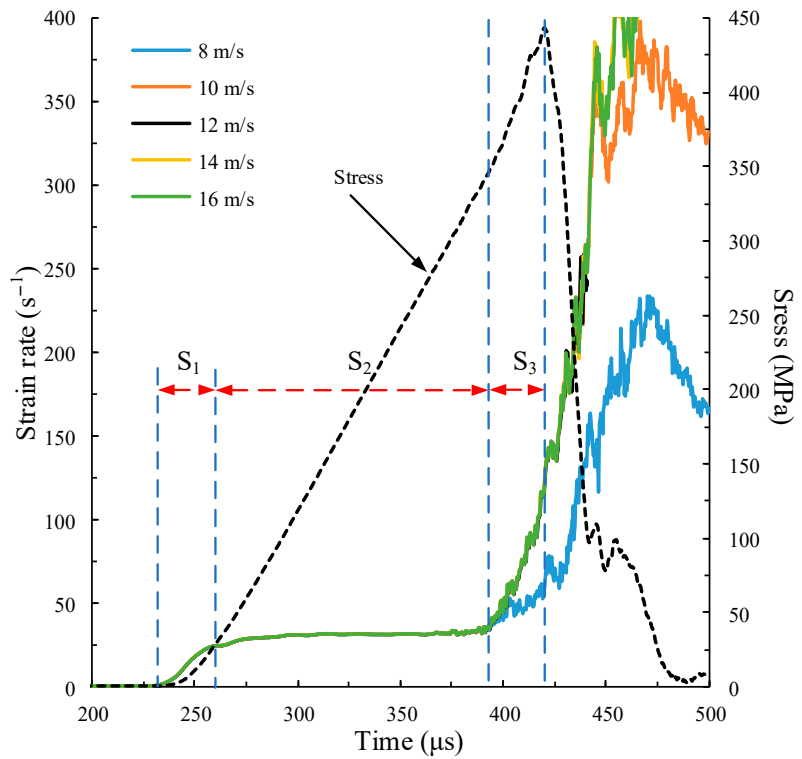

(b)

Figure 6. Cont. 


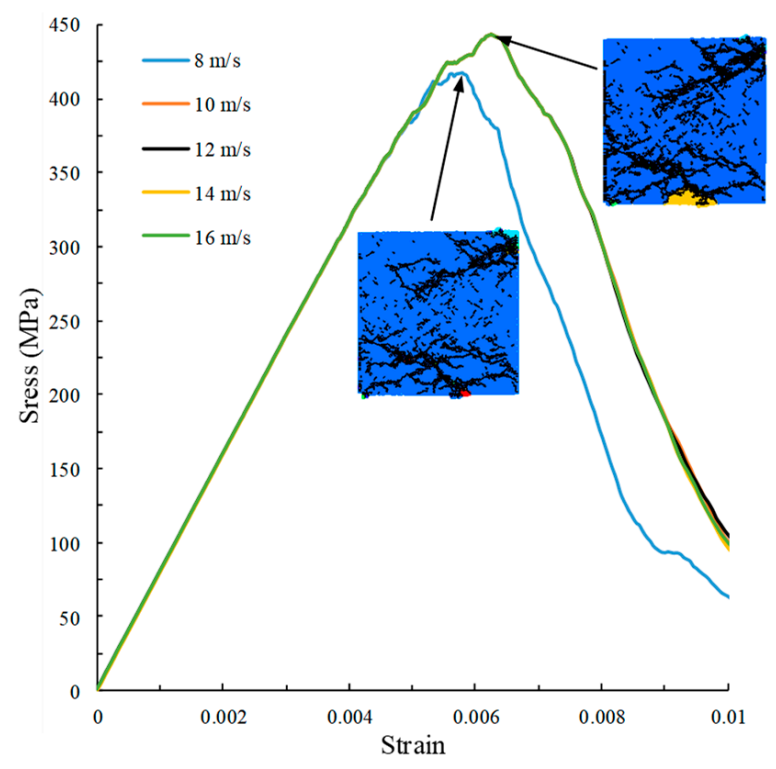

(c)

Figure 6. Calculation curve under different amplitudes. (a) Time history curves of incident stress wave; (b) time history curves of strain rate and stress; (c) stress-strain curve.

Figure 6a shows the time history curves of the stress monitored by measuring circle 1 on the incident bar. The following incident stress waves are taken from the monitoring data of measuring circle 1 . The shape of the time history curve of stress is consistent with its velocity pulse waveform. The slope of the curve loading stage, i.e., the incident wave stress rate $\dot{\sigma}_{\mathrm{i}}$, is the same, and $\dot{\sigma}_{\mathrm{i}}=2450 \mathrm{GPa} / \mathrm{s}$.

Figure $6 \mathrm{~b}$ shows the time history curve of the strain rate with the same slope but using the different amplitudes of the five groups of pulse curves. The curve overlap of the five groups is very high, indicating that the strain rate of the specimen remains unchanged when only changing the amplitude of the velocity pulse curve without changing the slope. The time history curve of strain rate in the loading stage is divided into three stages. The time history curve of the stress (the dotted line in Figure $6 \mathrm{~b}$ at $A_{\mathrm{v}}=12 \mathrm{~m} / \mathrm{s}$ is given to facilitate the division of the three stages. The first stage is the initial non-constant strain rate loading stage $S_{1}$, in which the strain rate increases sharply, and the specimen particles are dominated by the inertial effect. Under the axial dynamic load, part of the work of the external load is to provide kinetic energy to the particles so that the particles obtain axial acceleration. Due to the existence of the Poisson effect, particles will interact with adjacent particles, and adjacent particles will obtain radial acceleration. The load that provides acceleration to the particles is the inertial effect, which is part of the macro-bearing capacity [37]. The inertia effect can be characterized by strain rate gradient $\ddot{\varepsilon}_{\mathrm{c}}$ [56], which can be obtained by the derivative of strain rate $\dot{\varepsilon}_{\mathrm{c}}$ to time $t$. The strain rate gradient of the specimen in $S_{1} \ddot{\varepsilon}_{\mathrm{c}}=1.16 / \mathrm{s}^{2}$. The second stage is the constant strain rate loading stage $S_{2}$, where the specimen is subjected to constant strain rate loading. The strain rates $\dot{\varepsilon}_{\mathrm{c}}$ of the five groups of specimens are the same, $\dot{\varepsilon}_{\mathrm{c}}=30.98 / \mathrm{s}$. In this stage, the specimen particles keep moving at a uniform speed, and the strength has an exponential relation with the strain rate. Only when the rock deformation is in the state of constant strain rate can the results can be used as the constitutive relation [10]. The third stage is the non-constant strain rate stage $S_{3}$ of accelerated failure. At this time, the inner microcracks of the specimen gradually form macro cracks. The force on the specimen is unbalanced, and the inner particle motion intensifies. The acceleration caused by the interaction between particles accelerates the failure of the specimen. The inertia effect also plays a leading role in this stage. Since the inertia effect is a part of the macro-bearing capacity, the specimen's macro bearing capacity also increases at this stage. 
The stress-strain curve in Figure $6 \mathrm{c}$ shows that when the amplitude $A_{\mathrm{v}}=8 \mathrm{~m} / \mathrm{s}$, the peak stress $\sigma_{\mathrm{p}}=417.95 \mathrm{MPa}$, and the peak stress of the other four groups $\sigma_{\mathrm{p}}=442.86 \mathrm{MPa}$. The stress of the specimen is taken from the monitoring data of measuring circle 4 , the same below. Figure $6 \mathrm{c}$ also shows the distribution of specimen failure cracks at peak stress with $A_{\mathrm{V}}=8 \mathrm{~m} / \mathrm{s}$ and one of the other four groups. The failure modes of the other four groups are exactly the same, and the number of microcracks is 2499 . When $A_{\mathrm{v}}=8 \mathrm{~m} / \mathrm{s}$, the number of microcracks in the specimen is 2260 , and its failure mode is similar to that of the other four groups. It can be seen that compared with the failure mode when $A_{\mathrm{v}}=8 \mathrm{~m} / \mathrm{s}$, the other four groups are further damaged. In the previous study of rock dynamics, the strain rate was the only variable used to characterize the dynamics, meaning that the peak stress should be the same with the same strain rate. This assumption is inconsistent with the calculation results in this paper. The possible reason for this phenomenon is that a specimen has a critical interval of dynamic strength. When the amplitude is less than this critical interval, the specimen will not be damaged; when the amplitude is in this critical interval, the specimen will be damaged. Its dynamic strength will increase with the amplitude, but it is independent of the strain rate. This is because when the amplitude increases, the inner particle interaction force of the specimen increases, but the internal crack expands further before it has time to penetrate. When the amplitude is greater than this critical interval, the dynamic strength will not increase no matter how the amplitude increases because the inner cracks of the specimen have penetrated, and the stress-strain curve remains unchanged. Therefore, when the strain rate is used to characterize the dynamic stress of the specimen, whether it is in the critical interval should also be considered.

\subsection{Different Rise Times}

The SHPB impact numerical simulation test is carried out on the specimen using five groups of pulse curves with different rise times, as shown in Figure 5b. The calculation results are provided in Figure 7.

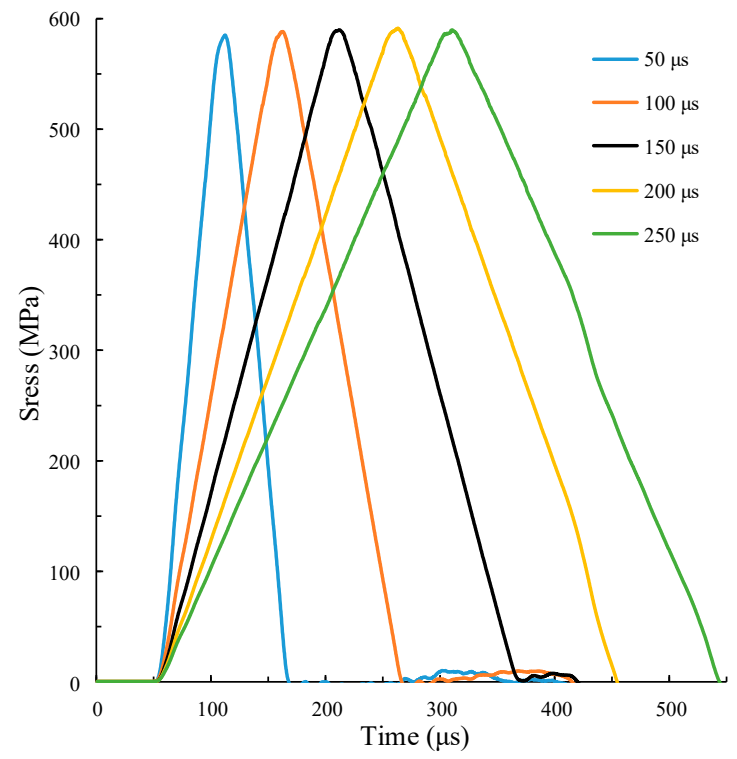

(a)

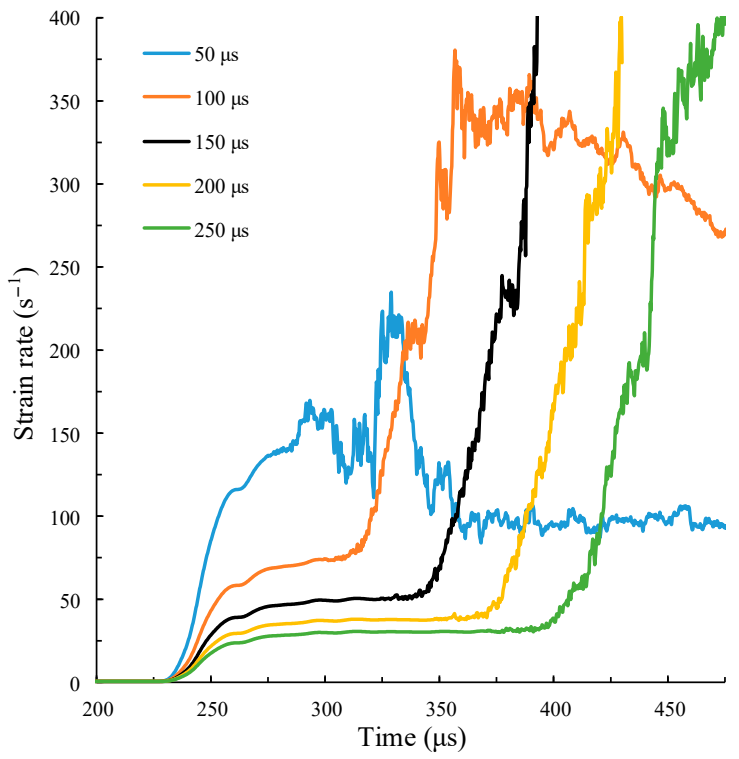

(b)

Figure 7. Cont. 


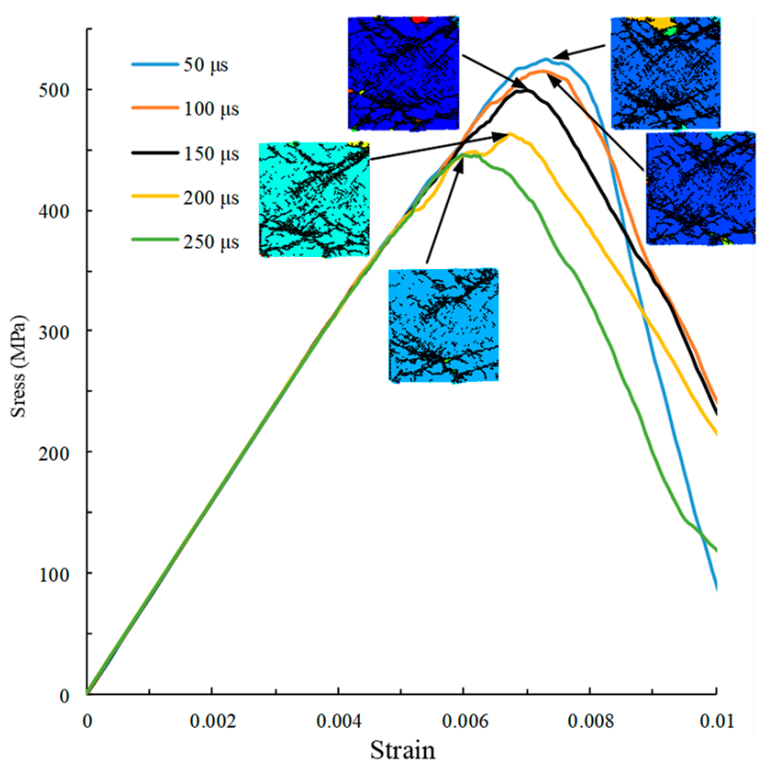

(c)

Figure 7. Curve calculations under different slopes. (a) Time history curves of incident stress wave; (b) time history curves of strain rate; (c) stress-strain curve.

Figure 7a shows the time history curves of the incident stress wave, where the curve shape is consistent with the velocity pulse waveform. The slopes of the five groups of stress wave curves are different, and their peak stresses $\sigma_{\mathrm{p}}$ are similar, $\sigma_{\mathrm{p}} \approx 589 \mathrm{MPa}$. Figure $7 \mathrm{~b}, \mathrm{c}$ show that with the amplitude unchanged, the strain rate and peak stress increase as the rise time of the pulse curve shortens. Compared with the analysis results in Section 3.2, the strain rate of the specimen is only related to the slope of the incident stress waveform (i.e., the incident wave stress rate, the derivative of stress to time) but independent of its amplitude. As illustrated in Figure $7 \mathrm{~b}$, when the curve rise time $t_{\mathrm{r}}=250 \mu \mathrm{s}$, the specimen can also maintain the constant strain rate loading. However, when the rise time is shortened to $50 \mu \mathrm{s}$, the specimen cannot maintain constant strain rate loading. Figure $7 \mathrm{c}$ shows the failure crack distributions of the specimen at the peak stress of the five groups of curves. It can be seen that the failure modes of the five groups are similar. The shorter the rise time, the greater the crushing degree of the specimen at the peak stress.

As shown in Figure 8a, the fitting degree between the incident wave stress rate $\dot{\sigma}_{\mathrm{i}}$ and specimen strain rate $\dot{\varepsilon}_{\mathrm{c}}$ is very high, $R^{2}=0.9997$.

The fitting degree is determined according to Equation (5):

$$
\dot{\sigma}_{\mathrm{i}}=0.084 \dot{\varepsilon}_{\mathrm{c}}-0.21, R^{2}=0.9997
$$

The strain rate of the specimen has a logarithmic relationship with the peak stress $[28,52]$. It is also possible to characterize the peak stress by the incident wave stress rate. In Figure $8 \mathrm{~b}$, the incident wave stress rate and strain rate of the specimen are used to fit the peak stress, and their fitting curves and degrees are very similar, as shown in Equation (6). Therefore, we believe that the strain rate of the specimen is only related to the slope of the incident stress waveform and is independent of its amplitude.

$$
\left\{\begin{array}{l}
\sigma_{\mathrm{p}}=115.21 \log _{10}\left(\dot{\sigma}_{\mathrm{i}}\right)+414.13, R^{2}=0.8502 \\
\sigma_{\mathrm{p}}=119.25 \log _{10}\left(\dot{\varepsilon}_{\mathrm{c}}\right)+280.85, R^{2}=0.8585
\end{array}\right.
$$

However, the fitting degree of the curve is not high, which may indicate that it is not appropriate to simply use strain rate or stress rate fitting and that the strain rate gradient should also be taken into account. 


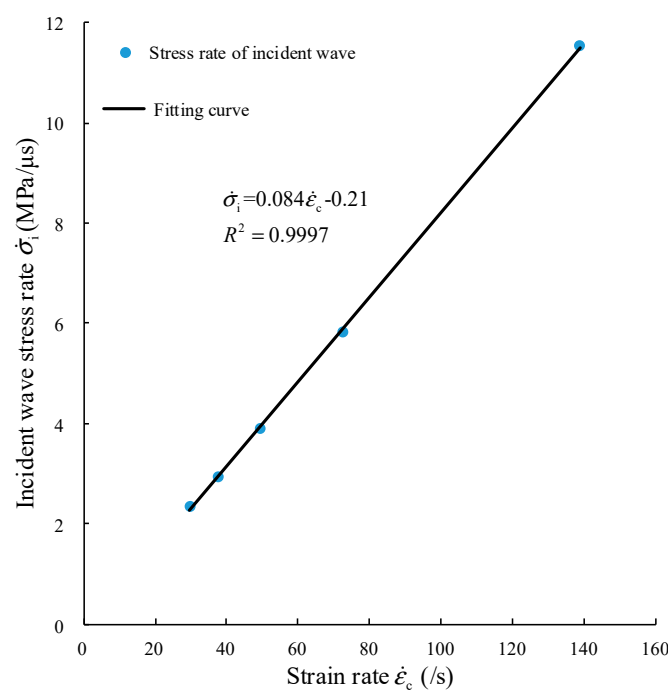

(a)

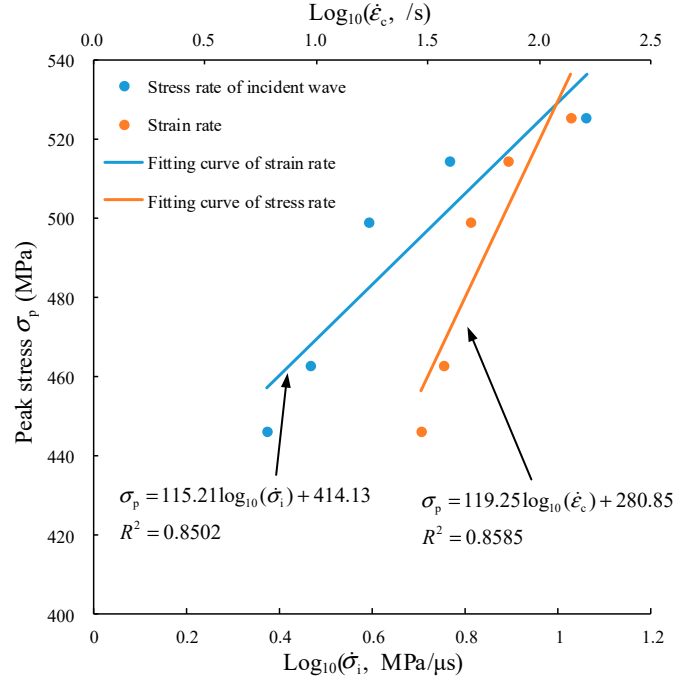

(b)

Figure 8. Fitting relationship between the incident wave stress rate and strain rate and peak stress. (a) Relationship between stress rate and strain rate; (b) relationship between peak stress and stress rate and strain rate.

\section{Force Pulse}

\subsection{Pulse Waveform}

In the force pulse waveform, the numerical simulation test is carried out by changing the amplitude $A_{\mathrm{f}}$, rise time $t_{\mathrm{r}}$, and upper bottom time $t_{\mathrm{u}}$ of the waveforms. Each case is divided into five groups, with a total of fifteen groups. In the five groups of waveforms with different amplitudes, the pulse slope $\dot{f}$ and upper bottom time $t_{\mathrm{u}}$ remain unchanged, $\dot{f}=250 \mathrm{~N} / \mathrm{s}$ and $t_{\mathrm{u}}=100 \mu \mathrm{s}$, respectively. The amplitudes $A_{\mathrm{f}}=3.0,3.5,4.0,4.5$ amd $5.0 \mathrm{kN}$, respectively. In the five groups of waveforms with different rise times, the amplitude $A_{\mathrm{f}}$ and upper bottom time $t_{\mathrm{u}}$ remain unchanged, $A_{\mathrm{f}}=4.0 \mathrm{kN}$ and $t_{\mathrm{u}}=100 \mu \mathrm{s}$, respectively. The rise time $t_{\mathrm{r}}=20 \mu \mathrm{s}, 30 \mu \mathrm{s}, 40 \mu \mathrm{s}, 50 \mu \mathrm{s}, 60 \mu \mathrm{s}$, respectively. In the five groups of waveforms with different upper bottom, the amplitude $A_{\mathrm{f}}$ and rise time $t_{\mathrm{r}}$ remain unchanged, $A_{\mathrm{f}}=4.0 \mathrm{kN}$ and $t_{\mathrm{r}}=40 \mu \mathrm{s}$, respectively. The upper bottom time $\mathrm{t}_{\mathrm{u}}=50,75,100,150$ and $200 \mu \mathrm{s}$, respectively. The pulse waveform is shown in Figure 9.

\subsection{Different Amplitudes}

The SHPB impact numerical simulation test is carried out on the specimen by using the amplitude of the five groups of different force pulse curves in Figure 9a. The calculation results are shown in Figure 10.

Figure 10a shows that the shape of the incident stress waveform is not consistent with that of the force pulse waveform. The amplitude and slope of the incident stress waveform increase with the amplitude of the pulse waveform amplitude. Since the rising slope of the five groups of pulse waveforms is the same, the incident stress waveforms almost completely overlap in the initial loading stage (marked in the figure). The strain rate gradient $\ddot{\varepsilon}_{\mathrm{c}}$ in the initial non-constant strain rate loading stage $S_{1}$ (marked when $A_{\mathrm{f}}=3.0 \mathrm{kN}$ ) in Figure $10 \mathrm{~b}$ is also relatively similar. This indicates that the strain rate gradient $\ddot{\varepsilon}_{\mathrm{c}}$ can be controlled by the rising slope of the force pulse waveform. When the upper bottom time of the pulse waveform acts continuously, the stress in the incident bar also increases gradually until the action time of the upper bottom ends. Therefore, the greater the amplitude of the pulse waveform, the greater the rate of stress increase in the incident bar, and the greater the slope and amplitude of the stress time history curve. According to the above analysis, the strain rate of the specimen in $S_{2}$ is related to the rising slope of the incident wave. Therefore, the strain rate increases with the incident wave amplitude in Figure 10b. 


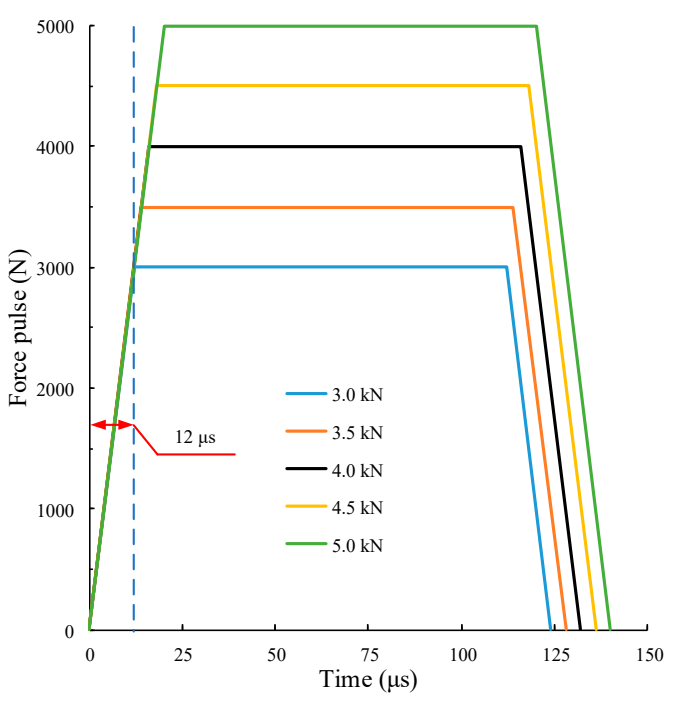

(a)

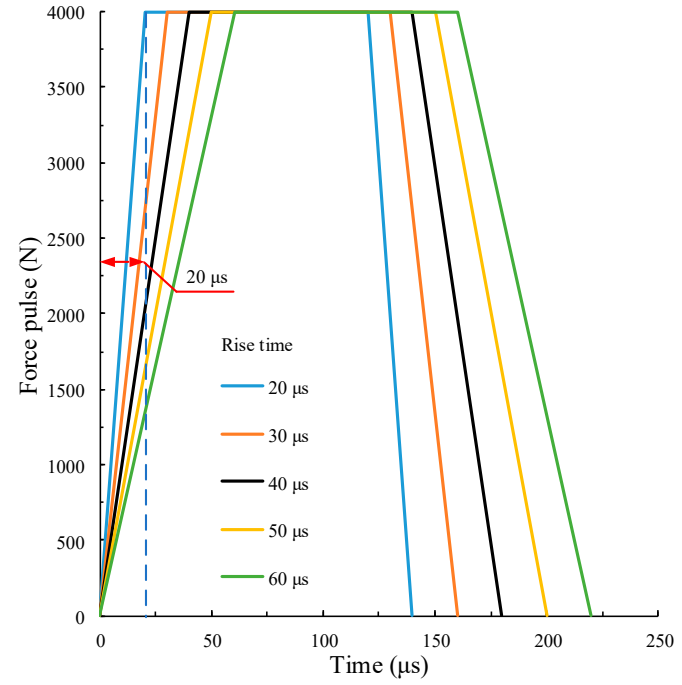

(b)

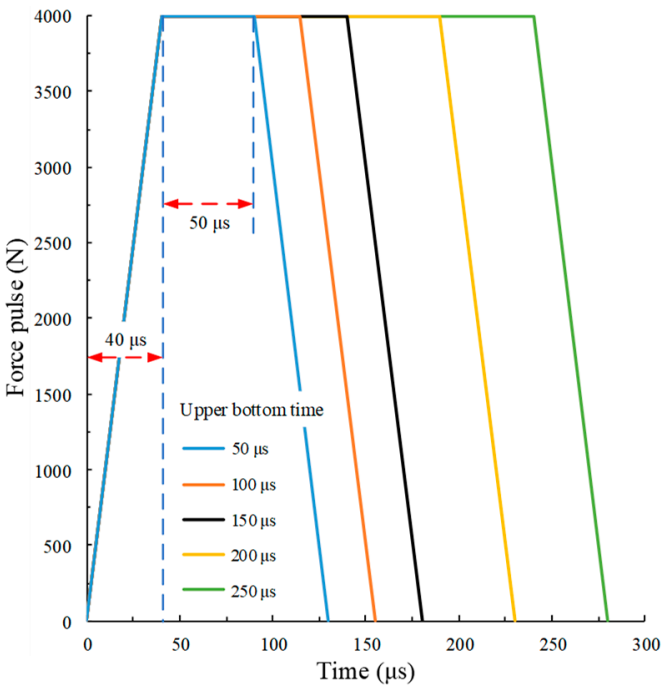

(c)

Figure 9. Velocity pulse waveform. (a) Different amplitudes; (b) different rise times; (c) different upper bottom times.

Although a certain characteristic of the incident waveform cannot be controlled by using force pulse waveforms with different amplitudes, the analysis shows that the rising slope of the force pulse waveform determines the strain rate gradient of the specimen, and the upper bottom time determines the amplitude of the incident stress wave. The simulation test scheme with different rise and upper bottom times is designed on this basis.

\subsection{Different Rise Time}

The different strain rate gradients $\ddot{\varepsilon}_{\mathrm{c}}$ can be obtained by changing the rise time while keeping the amplitude $A_{\mathrm{f}}$ and the rise time $t_{\mathrm{r}}$ of the force pulse waveform unchanged. However, when the rise time is too large, the rising slope of the incident waveform decreases, and the strain rate will also decrease. Thus, it is necessary to control the rise time to obtain different strain rate gradients at the same strain rate. According to our simulations, when $A_{\mathrm{f}}=4 \mathrm{kN}$ and $t_{\mathrm{r}} \leq 60 \mu \mathrm{s}$, the strain rate time history curve with the same strain rate and different strain rate gradients can be obtained. The force pulse waveform is shown in Figure 9b. The calculation results are shown in Figure 11. 


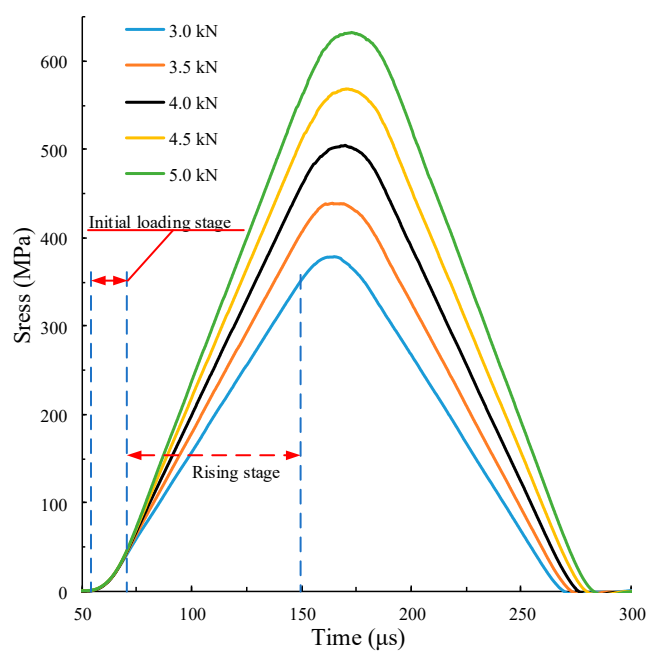

(a)

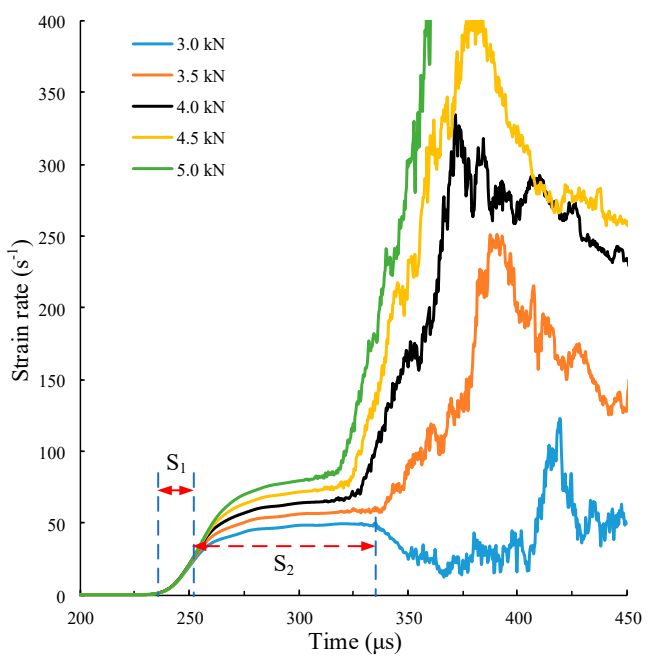

(b)

Figure 10. Calculation curve under different amplitudes. (a) Time history curves of incident stress wave; (b) time history curves of strain rate.

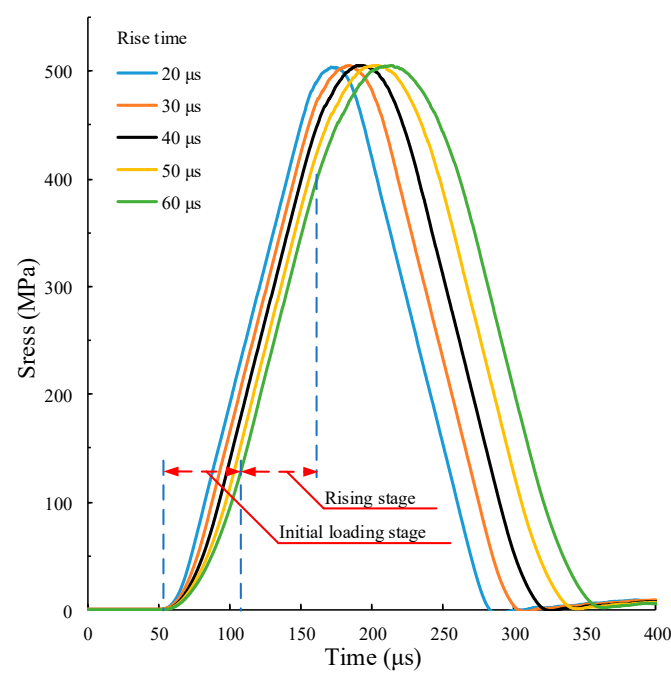

(a)

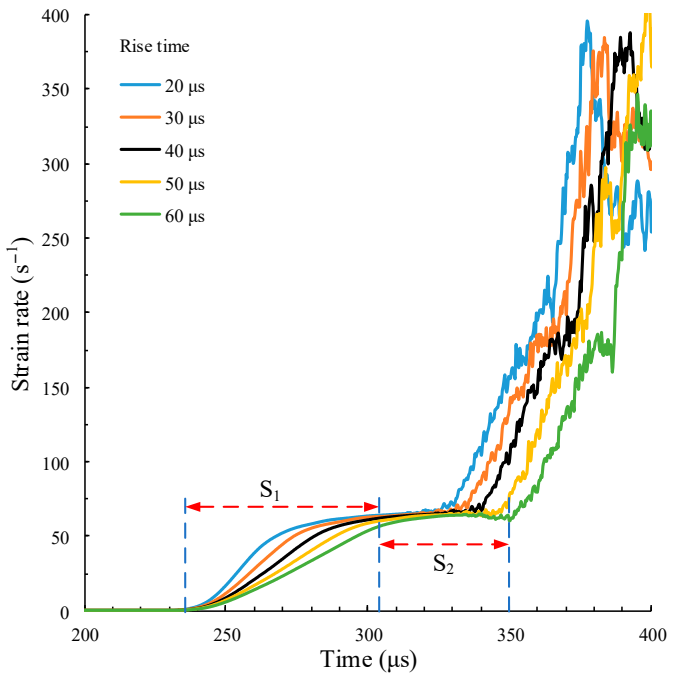

(b)

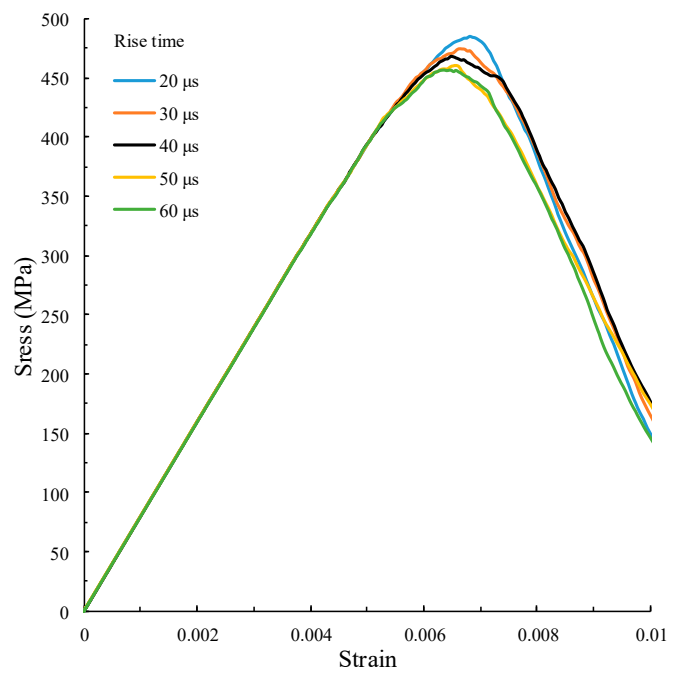

(c)

Figure 11. Curve calculations under different rise times. (a) Time history curves of incident stress wave; (b) time history curves of strain rate; (c) stress-strain curve. 
In Figure 11a, the duration of the initial loading stage of five incident stress waves increases with the rise time of the force pulse wave. The initial loading section when $t_{\mathrm{r}}=60 \mu \mathrm{s}$ is marked in the figure. The rise slope $\dot{\sigma}_{\mathrm{i}}$ and amplitude of the incident stress wave are the same, where $\dot{\sigma}_{\mathrm{i}}=5200 \mathrm{GPa} / \mathrm{s}$. In Figure $11 \mathrm{~b}$, the strain rates of the five curves in $S_{2}$ remain basically the same, $\dot{\varepsilon}_{\mathrm{c}}=58.8$ /s. The slope of the curve, i.e., the strain rate gradient $\ddot{\varepsilon}_{\mathrm{c}}$, in $S_{1}\left(t_{\mathrm{r}}=20 \mu \mathrm{s}\right.$ marked in the figure), is significantly different, indicating that different strain rate gradients can be obtained by controlling the loading slope with different rise times of force pulse waveform. The smaller $t_{\mathrm{r}}$ is, the greater $\ddot{\varepsilon}_{\mathrm{c}}$ is. The peak stress of the five curves in Figure 11c increases with the decrease of the rise time. Therefore, the greater the strain rate gradient $\ddot{\varepsilon}_{\mathrm{c}}$, that is, the greater the inertia effect, the greater the peak stress.

The strain rate gradient $\ddot{\varepsilon}_{\mathrm{c}}$ can be obtained by extracting the slope of five curves in $S_{1}$, Figure $11 b$. Since the strain rate gradient is caused by the acceleration between inner particles in the specimen, the peak stress $\sigma_{\mathrm{p}}$ and strain rate gradient $\ddot{\varepsilon}_{\mathrm{c}}$ are fitted by a linear function. The fitting curve is shown in Figure 12.

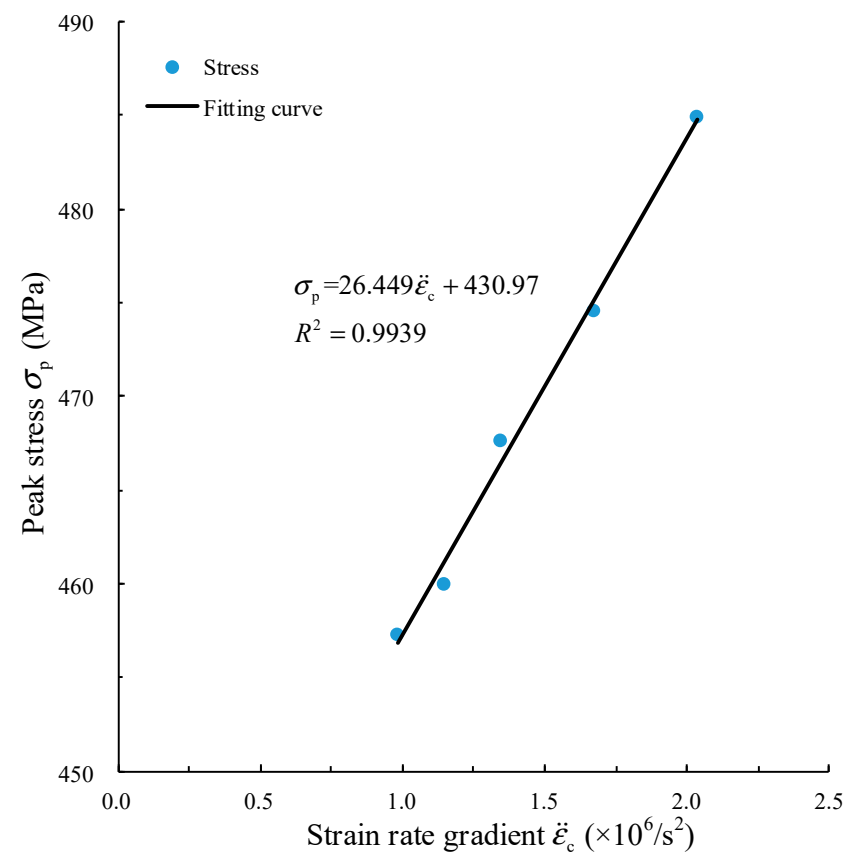

Figure 12. Fitting relation between peak stress and strain rate gradient.

The fitting relation between peak stress $\sigma_{\mathrm{p}}$ and strain rate gradient $\ddot{\varepsilon}_{\mathrm{c}}$ is shown in Equation (7).

$$
\sigma_{\mathrm{p}}=26.449 \ddot{\varepsilon}_{\mathrm{c}}+430.97, R^{2}=0.9939
$$

where the fitting degree $R^{2}$ reaches 0.9939 . The high fitting degree shows that there is a highly significant linear correlation between $\sigma_{\mathrm{p}}$ and $\ddot{\varepsilon}_{\mathrm{c}}$. When the rising slope of the force pulse waveform is large, the strength of the specimen is dominated by the inertia effect. Comparing the fitting degree between strain rate and peak strength in Equation (6), it can be determined that the inertia effect must not be ignored in SHPB.

\subsection{Different Upper Bottom Times}

The numerical simulation test of SHPB pulse is carried out on the specimen by using the upper bottom time of the five different force pulse waveforms in Figure 9c. The calculation results are shown in Figure 13. 


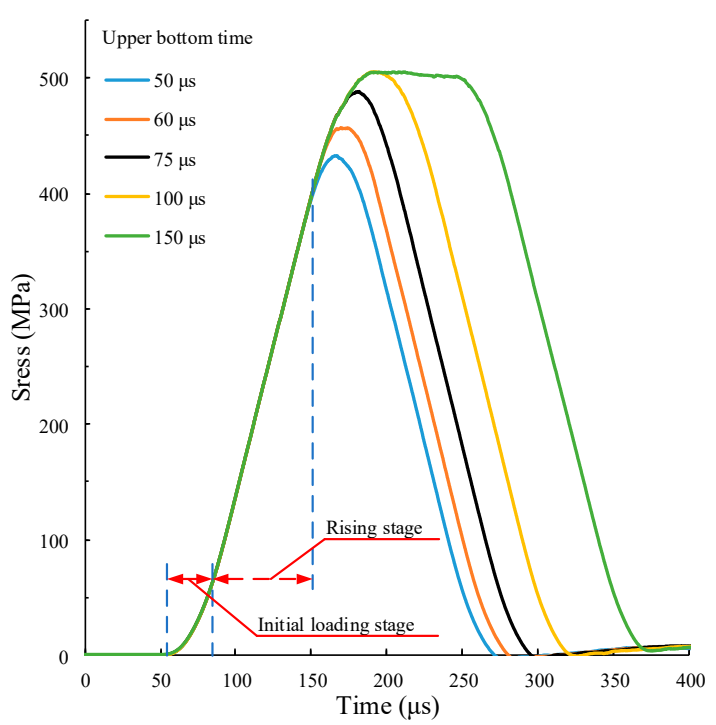

(a)

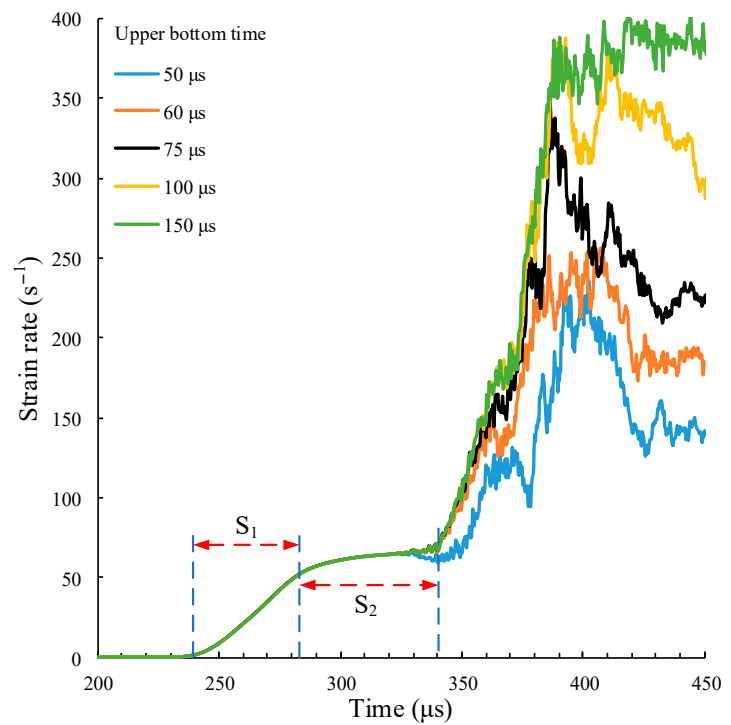

(b)

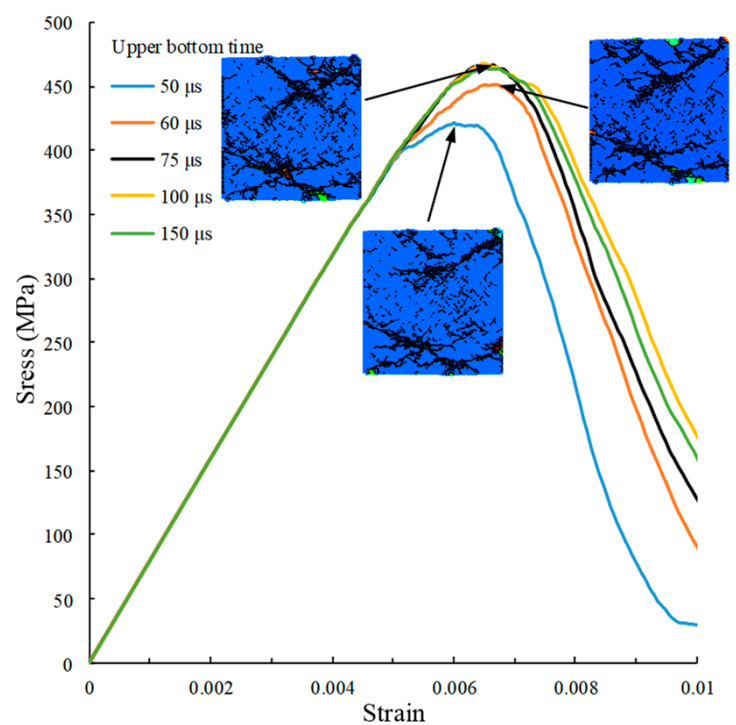

(c)

Figure 13. Curve calculations under different upper bottom times. (a) Time history curves of incident stress wave; (b) time history curves of strain rate; (c) stress-strain curve.

Figure 13a shows that the initial loading stage and rising stage of the five time history curves of incident stress waves are completely overlapped. Accordingly, in Figure 13b, the strain rate time history curves are overlapped in the $S_{1}$ and $S_{2}$ stages. Thus, the amplitude of the time history curve of the incident stress wave will increase with the upper bottom time of the force pulse waveform. When the upper bottom time $t_{\mathrm{u}} \geq 100 \mu \mathrm{s}$, the amplitude does not increase. Figure $13 \mathrm{c}$ shows that when $t_{\mathrm{u}}<75 \mu \mathrm{s}$, the peak stress of the specimen increases with the upper bottom time. When $t_{\mathrm{u}} \geq 75 \mu \mathrm{s}$, the peak stress does not increase. This is the same as the law obtained by using velocity pulse waveforms with different amplitudes in Section 3.2. On the one hand, the impact effect of the upper bottom time of the force pulse waveform and the amplitude of the velocity pulse waveform are the same. On the other hand, a critical interval for the dynamic bearing strength of the specimen is also identified. The figure shows the crushing morphology of specimens at different peak stresses. The crushing morphology of specimens is relatively similar, and the number of microcracks increases with the increase of peak stress. 


\section{Dynamic Strength Prediction Model}

According to the previous analysis, the strain rate and strain rate gradient of rock specimens will affect their dynamic strength. Here, they are regarded as independent variables, and a rock dynamic strength prediction model is established, where the strain rate $\dot{\varepsilon}_{\mathrm{c}}$ is fitted by a logarithmic function, and the strain rate gradient $\ddot{\varepsilon}_{\mathrm{c}}$ is fitted by a linear function. The prediction model is shown in Equation (8):

$$
\sigma_{\mathrm{p}}=a \log _{10}\left(\dot{\varepsilon}_{\mathrm{c}}\right)+b \ddot{\varepsilon}_{\mathrm{c}}+c
$$

where $a, b$, and $c$ are fitting values.

In the time history curves of strain rate obtained by using velocity pulse waveforms with different slopes in Section 3.3, the strain rates and strain rate gradients of the five curves are different. This prediction model is used to refit the curve in Figure 8, and a twodimensional fitting curve is adopted to facilitate visual expression. As shown in Figure 14, $\left(a \ln \left(\dot{\varepsilon}_{\mathrm{c}}\right)+b \ddot{\varepsilon}_{\mathrm{c}}\right)$ is set as the abscissa, and the fitting relation is shown in Equation (9):

$$
\sigma_{\mathrm{p}}=308.90 \log _{10}\left(\dot{\varepsilon}_{\mathrm{c}}\right)-28.98 \ddot{\varepsilon}_{\mathrm{c}}+21.85, R^{2}=0.9806
$$

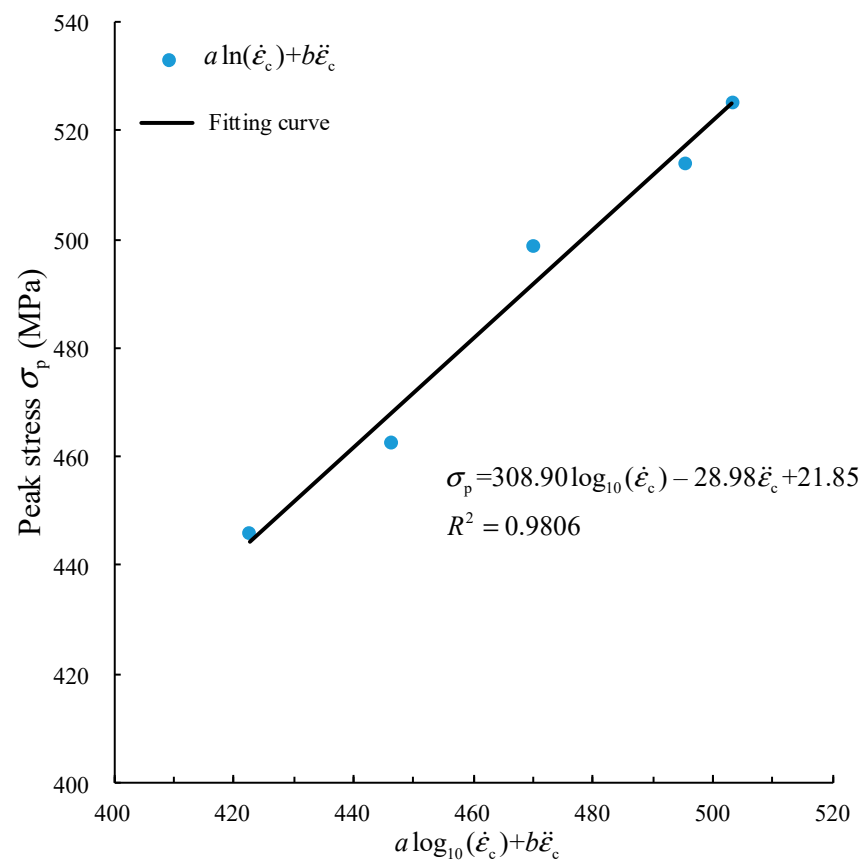

Figure 14. Fitting relationship between peak stress and strain rate and strain rate gradient.

As illustrated in Figure 14, the fitting curve obtained using the prediction model in Equation (8) can effectively describe the dynamic peak strength of the specimen under the impact of the velocity pulse waveform with different slopes. The fitting degree of Equation (9) $R^{2}=0.9806$ is also greatly improved compared with that of Equation (6) $R^{2}=0.8585$.

The simulation test data under the force pulse waveform are selected to verify the prediction model. As mentioned in Section 4.3, in the case where the amplitude and upper bottom time of the force pulse waveform remain unchanged, when the rise time is too large, both the strain rate gradient and the strain rate will decrease, while the amplitude $A_{\mathrm{f}}$ and upper bottom time $t_{\mathrm{u}}$ remain unchanged. The rise time $t_{\mathrm{r}}=50 \mu \mathrm{s}, 100 \mu \mathrm{s}, 150 \mu \mathrm{s}, 200 \mu \mathrm{s}, 300 \mu \mathrm{s}$, respectively. The calculation results are shown in Figure 15. 


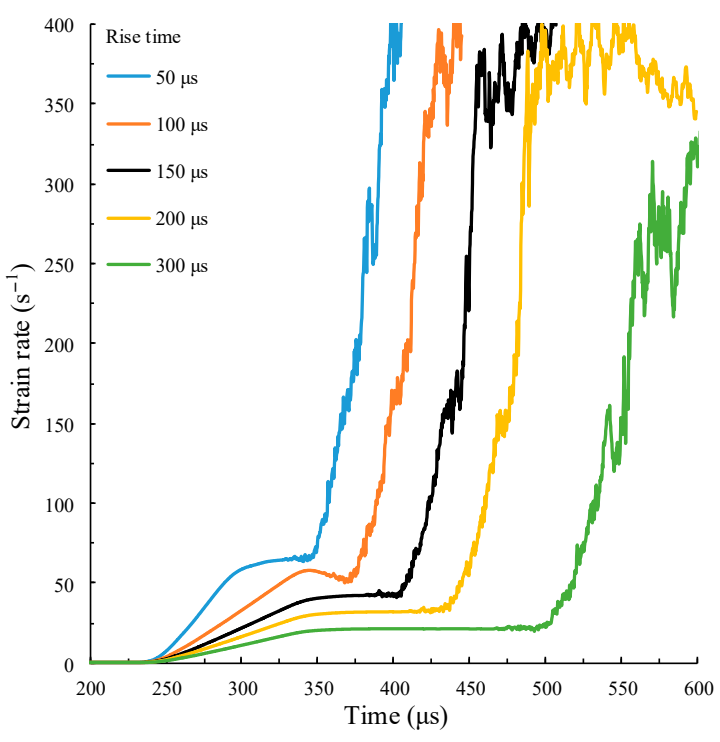

(a)

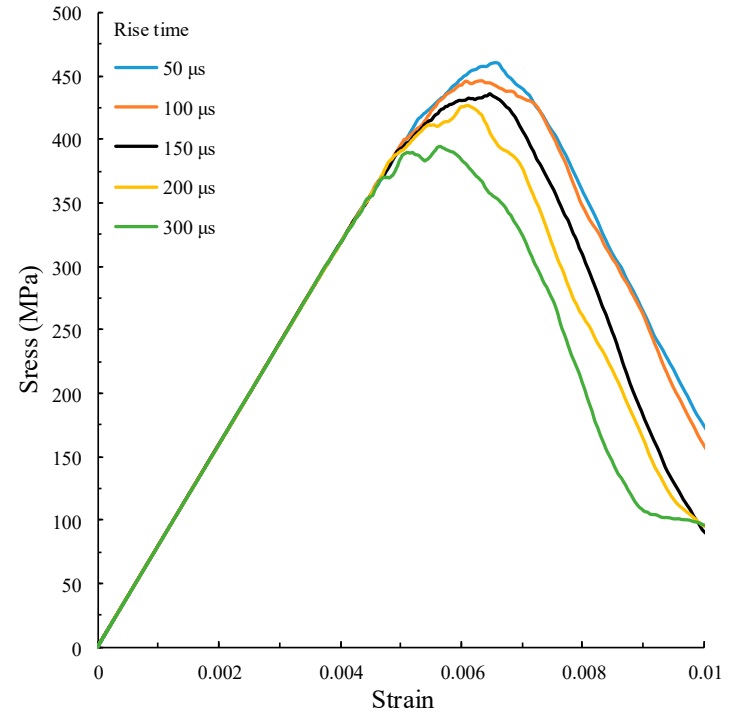

(b)

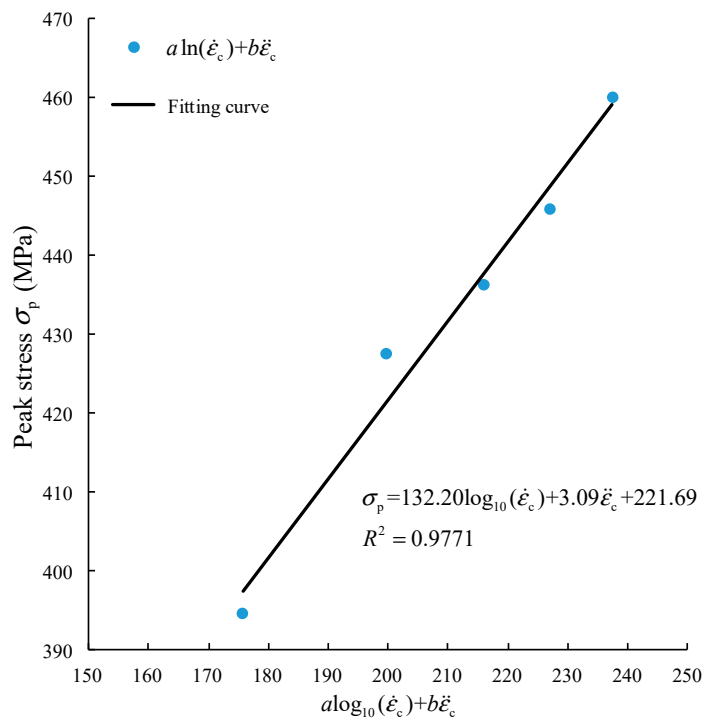

(c)

Figure 15. Calculation results under different rise times. (a) Time history curves of strain rate; (b) stress-strain curve; (c) fitting relation between peak stress and strain rate and strain rate gradient.

Figure $15 \mathrm{a}, \mathrm{b}$ show that when the amplitude and upper bottom time of the force pulse waveform remain unchanged but the rise time is too large, the strain rate gradient, strain rate, and peak strength will decrease with the increase of rise time. Figure $15 \mathrm{c}$ shows the fitting curve obtained by using the prediction model in Equation (8), and the fitting formula is as follows:

$$
\sigma_{\mathrm{p}}=132.20 \log _{10}\left(\dot{\varepsilon}_{\mathrm{c}}\right)+3.09 \ddot{\varepsilon}_{\mathrm{c}}+221.69, R^{2}=0.9771
$$

The fitting degree $R^{2}$ reaches 0.9771 , which indicates that the prediction model can effectively describe the dynamic peak strength of the specimen under the impact of a force pulse waveform with different rise times.

Lee's test results [47] are used to verify the reliability of the model. Three groups of data with the same sample size but different static compressive strengths are extracted. The 
sample size is $50 \mathrm{~mm} \times 50 \mathrm{~mm}$. The fitting result is shown in Figure 16, and the fitting formula is shown in Equation (11).

$$
\left\{\begin{array}{l}
\sigma_{P S 52}=73.75 \log _{10}\left(\dot{\varepsilon}_{c}\right)-4.4763 \ddot{\varepsilon}_{c}-71.31, R^{2}=0.6934 \\
\sigma_{P S 61}=35.65 \log _{10}\left(\dot{\varepsilon}_{c}\right)+3.5120 \ddot{\varepsilon}_{c}+10.5, R^{2}=0.9662 \\
\sigma_{P S 85}=-9.15 \log _{10}\left(\dot{\varepsilon}_{c}\right)+17.62 \ddot{\varepsilon}_{c}+106.80, R^{2}=0.8987
\end{array}\right.
$$

where $\sigma_{P S 52}, \sigma_{P S 61}, \sigma_{P S 85}$ represent the dynamic strength with static compressive strength of $51.90 \mathrm{MPa}, 61.35 \mathrm{MPa}$, and $85.10 \mathrm{MPa}$, respectively. The fitting degrees $R^{2}$ are $0.6934,0.9662$, and 0.8987 , respectively. It shows that the model proposed in this paper can accurately describe the dynamic strength of the specimen.

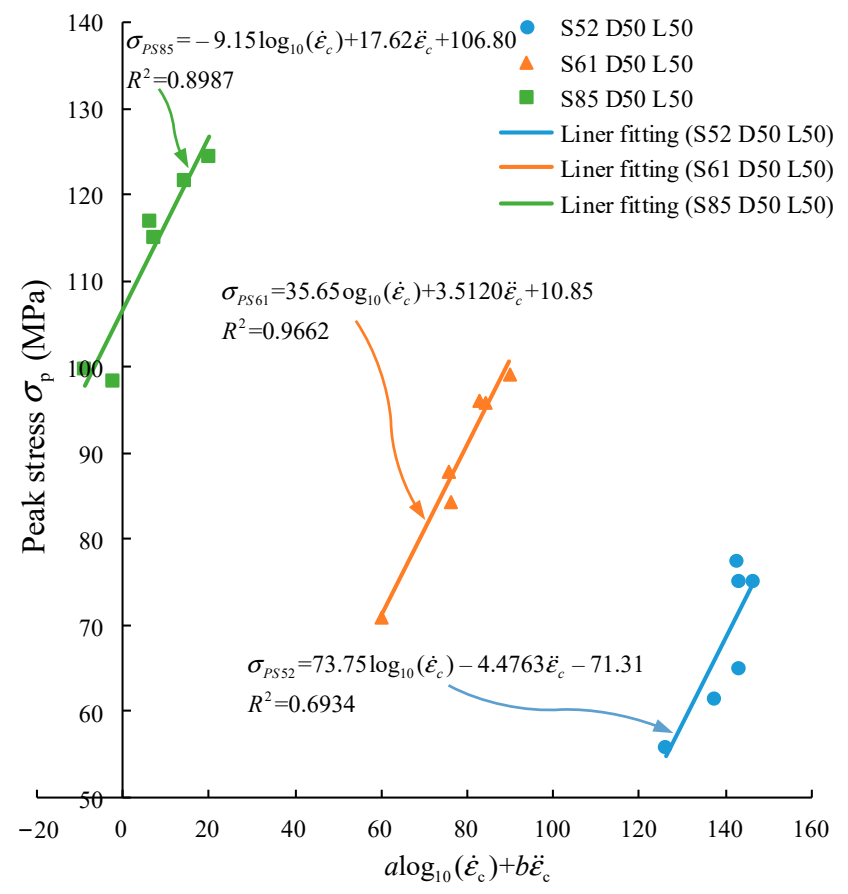

Figure 16. Comparison between the proposed model and the test results from Lee [47].

\section{Discussion}

The slope of the loading curve of the velocity pulse is acceleration, and the force is generated when the acceleration acts on the mass particles. If the slope remains constant, the particles will be subjected to a constant force. Comparing the loading modes of the two velocity pulses, it can be found that when loading with different amplitudes, the slope of each pulse curve is the same, the constant force and motion state of the particles are the same on the meso-scale, and the mechanical properties of the specimens are the same on the macro scale. However, when loading with different rise times, the slope of the pulse curve is different, and the constant force on the particles is also different. The greater the constant force, the greater the force between particles, and the greater the intensity of particle motion. Macroscopically, it shows the increase of strain rate and strength of the specimen.

The slope of the loading curve of the force pulse is a jerk, which is the change rate of acceleration with time. The shorter the rise time of the curve, the greater the slope, the faster the acceleration rate increases. The force between particles is increasing rapidly, and the strain rate gradient and inertia effect of the specimen are also increasing. When the amplitude and slope of the curve are kept constant, the force between particles gradually increases to the set value over time and remains constant. At this time, the length of the upper bottom determines the duration of the constant force, but it does not change the strain rate and strain rate gradient of the specimen. Therefore, the velocity pulse directly 
affects the movement rate of particles in the specimen, which determines the strain rate of the specimen. The force pulse directly affects the acceleration generated by particle interaction, which determines the strain rate gradient of the specimen.

By comparing the incident waveforms obtained by two loading types of velocity and force pulse, it is found that the triangular waveform of the incident waveform is similar to its velocity pulse, while the incident wave waveform obtained by the trapezoidal shape of the force pulse is similar to the sine waveform. In the "initial loading stage" of the sine waveform, there is acceleration between particles, and the mechanical properties of the specimen are determined by the acceleration (i.e., inertia effect). The nonlinear characteristic can be used to control the strain rate gradient of the specimen. According to this character, the strain rate gradient can be fixed and the strain rate can be changed, as shown in Figure 10b, or the strain rate can be fixed and the strain rate gradient can be changed, as shown in Figure 11b. However, a triangular wave can not fix one parameter and change the other at the same time. Different slopes will result in different strain rates and strain rate gradients, as shown in Figure $7 \mathrm{~b}$. Because there is no nonlinear characteristic of "initial loading section" in a triangular wave, the strain rate effect and inertia effect of the specimen are effectively controlled. Therefore, the trapezoidal shape of force pulse is more suitable for SHPB research.

\section{Conclusions}

A numerical simulation of rock SHPB was carried out in this work, based on the characteristics of the pulse waveform. The effects of different pulse types and pulse waveforms on the dynamic response characteristics of specimens were discussed. The following conclusions were obtained:

1. There is a critical interval of rock dynamic strength. Below the critical interval, the specimen will not be damaged. In the critical interval, the dynamic strength of the specimen is independent of the strain rate but increases with the amplitude of the incident stress wave. When the critical interval is exceeded, the dynamic strength is determined by strain rate and strain rate gradient.

2. The strain rate of the specimen is only related to the slope of the incident stress wave and is independent of its amplitude. Additionally, the inertia effect cannot be eliminated in SHPB.

3. The slope of the velocity pulse waveform determines the strain rate of the specimen. The slope of the force pulse waveform determines the strain rate gradient of the specimen, and the upper bottom time determines the strain rate of the specimen. The two pulse types can achieve the same impact effect by controlling the waveform shape.

4. A dynamic strength prediction model of rock-like brittle materials is proposed. The model considers the effects of strain rate and strain rate gradient and is verified.

Author Contributions: Conceptualization, B.S., R.C., Z.Z. and N.W.; methodology, B.S. and Y.H.; software, B.S. and Y.H.; validation, B.S. and R.C.; formal Analysis, B.S., R.C. and N.W.; investigation, N.W. and Y.H.; resources, B.S., Y.P. and Z.Z.; data curation, B.S. and N.W.; writing-original draft preparation, B.S.; writing-review and editing, B.S., R.C., Z.Z., Y.P. and N.W.; visualization, Y.H.; supervision, R.C., Z.Z., Y.P. and N.W.; project administration, R.C.; funding acquisition, R.C., Z.Z., Y.P. and N.W. All authors have read and agreed to the published version of the manuscript.

Funding: This study was supported by the National Natural Science Foundation of China (Grant No. 52108448 and 51878249), and the Science and Technology Planning Project of Shenzhen Municipality (Grant No. JCYJ20190806144603586).

Institutional Review Board Statement: Not applicable.

Informed Consent Statement: Not applicable.

Data Availability Statement: Not applicable. 
Conflicts of Interest: The authors declare no conflict of interest. The funders had no role in the design of the study; in the collection, analyses, or interpretation of data; in the writing of the manuscript, and in the decision to publish the results.

\section{References}

1. Wu, N.; Zhu, Z.; Zhang, C.; Luo, Z. Dynamic behavior of rock joint under different impact loads. KSCE J. Civ. Eng. 2019, 23, 541-548. [CrossRef]

2. Li, S.H.; Zhu, W.C.; Niu, L.L.; Yu, M.; Chen, C.F. Dynamic characteristics of green sandstone subjected to repetitive impact loading: Phenomena and mechanisms. Rock Mech. Rock Eng. 2018, 51, 1921-1936. [CrossRef]

3. Wu, N.; Zhu, Z.; Zhou, Y.; Gao, S. A comparative study on rock properties in splitting and compressive dynamic tests. Shock Vib. 2018, 2018, 1-12. [CrossRef]

4. Cotsovos, D.M.; Pavlović, M.N. Numerical investigation of concrete subjected to compressive impact loading. Part 2: Parametric investigation of factors affecting behaviour at high loading rates. Comput. Struct. 2008, 86, 164-180. [CrossRef]

5. Cho, S.H.; Ogata, Y.; Kaneko, K. Strain-rate dependency of the dynamic tensile strength of rock. Int. J. Rock Mech. Min. 2003, 40, 763-777. [CrossRef]

6. Zhao, J.; Li, H.B. Experimental determination of dynamic tensile properties of a granite. Int. J. Rock Mech. Min. 2000, 37, 861-866. [CrossRef]

7. Jiang, T.Z.; Xue, P.; Butt, H.S.U. Pulse shaper design for dynamic testing of viscoelastic materials using polymeric SHPB. Int. J. Impact Eng. 2015, 79, 45-52. [CrossRef]

8. Rong, Z.; Sun, W.; Zhang, Y. Dynamic compression behavior of ultra-high performance cement based composites. Int. J. Impact Eng. 2010, 37, 515-520. [CrossRef]

9. Malvern, L.E.; Ross, C.A. Dynamic Response of Concrete Andconcrete Structures; Department of Engineering Sciences, Florida University: Gainesville, FL, USA, 1986.

10. Li, X.B.; Lok, T.S.; Zhao, J.; Zhao, P.J. Oscillation elimination in the Hopkinson bar apparatus and resultant complete dynamic stress-strain curves for rocks. Int. J. Rock Mech. Min. 2000, 37, 1055-1060. [CrossRef]

11. Lee, O.S.; Kim, S.H.; Han, Y.H. Thickness effect of pulse shaper on dynamic stress equilibrium and dynamic deformation behavior in the polycarbonate using SHPB technique. J. Exp. Mech. 2006, 21, 51-60. [CrossRef]

12. Chen, W.; Luo, H.; Abadie, C. Dynamic compressive responses of intact and damaged ceramics from a single Split Hopkinson pressure bar experiment. Exp. Mech. 2004, 44, 295-299. [CrossRef]

13. Yang, G.; Chen, X.; Xuan, W.; Chen, Y. Dynamic compressive and splitting tensile properties of concrete containing recycled tyre rubber under high strain rates. Sädhanā 2018, 43,1-13. [CrossRef]

14. Luo, G.; Wu, C.; Xu, K.; Liu, L.; Chen, W. Development of dynamic constitutive model of epoxy resin considering temperature and strain rate effects using experimental methods. Mech. Mater. 2021, 159, 1-15. [CrossRef]

15. Jiang, J.; Xu, J.; Zhang, Z.; Chen, X. Rate-dependent compressive behavior of EPDM insulation: Experimental and constitutive analysis. Mech. Mater. 2016, 96, 30-38. [CrossRef]

16. Bagher Shemirani, A.; Naghdabadi, R.; Ashrafi, M.J. Experimental and numerical study on choosing proper pulse shapers for testing concrete specimens by Split Hopkinson pressure bar apparatus. Constr. Build. Mater. 2016, 125, 326-336. [CrossRef]

17. Vecchio, K.S.; Jiang, F. Improved pulse shaping to achieve constant strain rate and stress equilibrium in Split-Hopkinson pressure bar testing. Metall. Mater. Trans. A 2007, 38, 2655-2665. [CrossRef]

18. Frew, D.J.; Forrestal, M.J.; Chen, W. Pulse shaping techniques for testing brittle materials with a Split Hopkinson pressure bar. Exp. Mech. 2002, 42, 93-106. [CrossRef]

19. Sun, B.; Ping, Y.; Zhu, Z.; Jiang, Z.; Wu, N. Experimental study on the dynamic mechanical properties of large-diameter mortar and concrete subjected to cyclic impact. Shock Vib. 2020, 2020, 1-9. [CrossRef]

20. Zhang, H.; Liu, Y.; Sun, H.; Wu, S. Transient dynamic behavior of polypropylene fiber reinforced mortar under compressive impact loading. Constr. Build. Mater. 2016, 111, 30-40. [CrossRef]

21. Lok, T.S.; Li, X.B.; Liu, D.; Zhao, P.J. Testing and response of large diameter brittle materials subjected to high strain rate. J. Mater. Civ. Eng. 2002, 14, 262-269. [CrossRef]

22. Dai, F.; Xu, Y.; Zhao, T.; Xu, N. Loading-rate-dependent progressive fracturing of cracked chevron- notched Brazilian disc specimens in Split Hopkinson pressure bar tests. Int. J. Rock Mech. Min. 2016, 88, 49-60. [CrossRef]

23. Zhou, Z.; Jiang, Y.; Zou, Y.; Wong, L. Degradation mechanism of rock under impact loadings by integrated investigation on crack and damage development. J. Cent. South Univ. 2014, 21, 4646-4652. [CrossRef]

24. Kucewicz, M.; Baranowski, P.; Małachowski, J. Dolomite fracture modeling using the Johnson-Holmquist concrete material model: Parameter determination and validation. J. Rock Mech. Geotech. Eng. 2021, 13, 335-350. [CrossRef]

25. Jankowiak, T.; Rusinek, A.; Voyiadjis, G.Z. Modeling and design of SHPB to characterize brittle materials under compression for high strain rates. Materials 2020, 13, 2191. [CrossRef]

26. Baranowski, P.; Janiszewski, J.; Malachowski, J. Study on computational methods applied to modelling of pulse shaper in Split-Hopkinson bar. Arch. Mech. 2014, 66, 429-452.

27. Comite Euro-International du Beton. CEB-FIP Model Code 1990; Redwood Books: Trowbridge, Wiltshire, UK, 1993. 
28. Zhou, J.; Ge, L. Effect of strain rate and water-to-cement ratio on compressive mechanical behavior of cement mortar. J. Cent. South Univ. 2015, 22, 1087-1095. [CrossRef]

29. Joo Kim, D.; Sirijaroonchai, K.; El-Tawil, S.; Naaman, A.E. Numerical simulation of the Split Hopkinson pressure bar test technique for concrete under compression. Int. J. Impact. Eng. 2010, 37, 141-149. [CrossRef]

30. Hao, Y.; Hao, H.; Jiang, G.P.; Zhou, Y. Experimental confirmation of some factors influencing dynamic concrete compressive strengths in high-speed impact tests. Cem. Concr. Res. 2013, 52, 63-70. [CrossRef]

31. Hamdia, K.M.; Msekh, M.A.; Silani, M.; Vu-Bac, N.; Zhuang, X.; Nguyen-Thoi, T.; Rabczuk, T. Uncertainty quantification of the fracture properties of polymeric nanocomposites based on phase field modeling. Compos. Struct. 2015, 133, 1177-1190. [CrossRef]

32. Xing, H.Z.; Zhang, Q.B.; Ruan, D.; Dehkhoda, S.; Lu, G.X.; Zhao, J. Full-field measurement and fracture characterisations of rocks under dynamic loads using high-speed three-dimensional digital image correlation. Int. J. Impact. Eng. 2018, 113, 61-72. [CrossRef]

33. Rossi, P.; Toutlemonde, F. Effect of loading rate on the tensile behaviour of concrete: Description of the physical mechanisms Mater. Struct. 1996, 29, 116-172. [CrossRef]

34. Kipp, M.E.; Grady, D.E.; Chen, E.P. Strain-rate dependent fracture initiation. Int. J. Fract. 1980, 16, 471-478. [CrossRef]

35. Guo, Y.B.; Gao, G.F.; Jing, L.; Shim, V.P.W. Response of high-strength concrete to dynamic compressive loading. Int. J. Impact Eng. 2017, 108, 114-135. [CrossRef]

36. Zhou, X.Q.; Hao, H. Modelling of compressive behaviour of concrete-like materials at high strain rate. Int. J. Solids Struct. 2008, 45, 4648-4661. [CrossRef]

37. Lu, D.; Wang, G.; Du, X.; Wang, Y. A nonlinear dynamic uniaxial strength criterion that considers the ultimate dynamic strength of concrete. Int. J. Impact Eng. 2017, 103, 124-137. [CrossRef]

38. Xie, Y.; Fu, Q.; Zheng, K.; Yuan, Q.; Song, H. Dynamic mechanical properties of cement and asphalt mortar based on SHPB test. Constr. Build. Mater. 2014, 70, 217-225. [CrossRef]

39. Xu, H.; Wen, H.M. Semi-empirical equations for the dynamic strength enhancement of concrete-like materials. Int. J. Impact Eng. 2013, 60, 76-81. [CrossRef]

40. Li, Q.M.; Meng, H. About the dynamic strength enhancement of concrete-like materials in a Split Hopkinson pressure bar test. Int. J. Solids Struct. 2003, 40, 343-360. [CrossRef]

41. Katayama, M.; Itoh, M.; Tamura, S.; Beppu, M.; Ohno, T. Numerical analysis method for the RC and geological structures subjected to extreme loading by energetic materials. Int. J. Impact Eng. 2007, 34, 1546-1561. [CrossRef]

42. Hao, Y.; Zhang, X.; Hao, H. Numerical analysis of concrete material properties at high strain rate under direct tension. Procedia Eng. 2011, 14, 336-343. [CrossRef]

43. Hao, Y.; Hao, H.; Li, Z.X. Influence of end friction confinement on impact tests of concrete material at high strain rate. Int. J. Impact Eng. 2013, 60, 82-106. [CrossRef]

44. Hao, Y.; Hao, H. Numerical evaluation of the influence of aggregates on concrete compressive strength at high strain rate. Int. J. Prot. Struct. 2011, 2, 177-206. [CrossRef]

45. Al-Salloum, Y.; Almusallam, T.; Ibrahim, S.M.; Abbas, H.; Alsayed, S. Rate dependent behavior and modeling of concrete based on SHPB experiments. Cem. Concr. Compos. 2015, 55, 34-44. [CrossRef]

46. Kim, K.; Lee, S.; Cho, J. Effect of maximum coarse aggregate size on dynamic compressive strength of high-strength concrete. Int. J. Impact Eng. 2019, 125, 107-116. [CrossRef]

47. Lee, S.; Kim, K.; Park, J.; Cho, J. Pure rate effect on the concrete compressive strength in the Split Hopkinson pressure bar test. Int. J. Impact Eng. 2018, 113, 191-202. [CrossRef]

48. Itasca Consulting Group Inc. PFC2D (Particle Flow Code in 2D) Theory and Background; Itasca Consulting Group Inc.: Minneapolis, MN, USA, 2008.

49. Yang, S.Q.; Tian, W.L.; Huang, Y.H.; Ranjith, P.G.; Ju, Y. An experimental and numerical study on cracking behavior of brittle sandstone containing two non-coplanar fissures under uniaxial compression. Rock Mech. Rock Eng. 2016, 49, 1497-1515. [CrossRef]

50. Zhou, Z.; Zhao, Y.; Jiang, Y.; Zou, Y.; Cai, X.; Li, D. Dynamic behavior of rock during its post failure stage in SHPB tests. Trans. Nonferrous Met. Soc. China 2017, 27, 184-196. [CrossRef]

51. Li, X.; Zou, Y.; Zhou, Z. Numerical simulation of the rock SHPB test with a special shape striker based on the discrete element method. Rock Mech. Rock Eng. 2014, 47, 1693-1709. [CrossRef]

52. Qin, C.; Zhang, C. Numerical study of dynamic behavior of concrete by meso-scale particle element modeling. Int. J. Impact Eng. 2011, 38, 1011-1021. [CrossRef]

53. Qiu, J.; Li, D.; Li, X.; Zhou, Z. Dynamic fracturing behavior of layered rock with different inclination angles in SHPB tests. Shock Vib. 2017, 2017, 1-12. [CrossRef]

54. Potyondy, D.O.; Cundall, P.A. A bonded-particle model for rock. Int. J. Rock Mech. Min. 2004, 41, 1329-1364. [CrossRef]

55. Du, H.; Dai, F.; Xu, Y.; Liu, Y.; Xu, H. Numerical investigation on the dynamic strength and failure behavior of rocks under hydrostatic confinement in SHPB testing. Int. J. Rock Mech. Min. 2018, 108, 43-57. [CrossRef]

56. Gorham, D.A. Specimen inertia in high strain-rate compression. J. Physics. D Appl. Phys. 1989, 22, 1888-1893. [CrossRef] 